Portland State University

PDXScholar

Winter 3-13-2013

\title{
Map-based Probabilistic Infinite Slope Analysis of the Stephens Creek Watershed, Portland, Oregon
}

Ryan Andrew Cole

Portland State University

Follow this and additional works at: https://pdxscholar.library.pdx.edu/open_access_etds

Part of the Geology Commons, Soil Science Commons, and the Water Resource Management Commons

Let us know how access to this document benefits you.

\section{Recommended Citation}

Cole, Ryan Andrew, "Map-based Probabilistic Infinite Slope Analysis of the Stephens Creek Watershed, Portland, Oregon" (2013). Dissertations and Theses. Paper 625.

https://doi.org/10.15760/etd. 625

This Thesis is brought to you for free and open access. It has been accepted for inclusion in Dissertations and Theses by an authorized administrator of PDXScholar. Please contact us if we can make this document more accessible: pdxscholar@pdx.edu. 
Map-based Probabilistic Infinite Slope Analysis of the Stephens Creek

Watershed, Portland, Oregon

by

Ryan Andrew Cole

A thesis submitted in partial fulfillment of the requirements for the degree of

Master of Science

in

Geology

Thesis Committee:

Scott Burns, Chair

Robert B. Perkins

Ericka Koss

Portland State University

2013 


\begin{abstract}
The Stephens Creek Watershed in southwest Portland, Oregon was chosen by
\end{abstract} the city as a pilot project for urban stream restoration efforts, and the infiltration of stormwater was identified as a potential restoration strategy. The Stephens Creek Watershed has historically been known to be unstable during high precipitation events (Burns, 1996), and the need to address the response of slope stability to anthropogenically-driven changing groundwater conditions is the focus of this study. Airborne light detection and ranging (LiDAR) and geotechnical data from the City of Portland were employed to create a high resolution $\left(0.84 \mathrm{~m}^{2}\right)$ physics-based probabilistic slope stability model for this watershed, using the map-based probabilistic infinite slope analysis program PISA-m (Haneberg, 2007). Best and worst case models were run using fully dry and fully saturated soil conditions, respectively. Model results indicate that $96.3 \%$ of the watershed area had a probability $\leq 0.25$ that the slope factor of safety (FOS) was $\leq 1$ for fully dry conditions, compared to $76.4 \%$ for fully saturated conditions. Areas that had a probability $\geq 0.25$ that the slope factor of safety (FOS) was $\leq$ 1 were found to occur mainly along cut/fill slopes as well as within the deeply incised canyons of Stephens Creek and its tributaries. An infiltration avoidance map was derived to define areas that appear to be unsuitable for infiltration. Based on these results, it is recommended that stormwater continues to be directed to existing sewer infrastructure and that the "storm water disconnect" restoration approach not be used by the city. 


\section{Acknowledgements}

This work would not have been possible if it were not for a small handful of individuals. The impetus for this work was Ericka Koss, CEG, PE, of the City of Portland's Bureau of Environmental Services, whose engineering experience in the West Hills deemed this research necessary. The ability to model slope failure in this work is due to Dr. William Haneberg, who allowed the use of his own software, PISA-m, free of charge. The completion of this work would not have happened were it not for my mentor at the U.S. Forest Service, Bob Fujimoto, who ensured that time was given to work on this thesis even whilst being employed full-time. The valuable knowledge and experience gained from the entirety of the faculty and staff that I had the opportunity to work with during my tenure at Portland State University cannot be stated with enough emphasis. This is especially true of Dr. Ben Perkins, who contributed significant amounts of time and energy towards the completion of my undergraduate honors thesis. The experience gained from that work set the tone for this effort. My wife, Sara Cole, provided consistent encouragement and motivation, without which this thesis may not have come to fruition. Lastly, the motivation to attend grad school came from Dr. Scott Burns, whose passion and enthusiasm for geology inspired the furtherance of my education, and the desire to become a professional geologist. 


\section{Table of Contents}

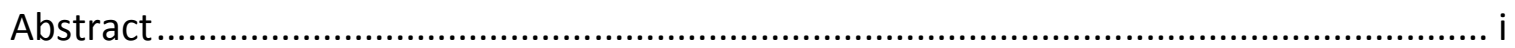

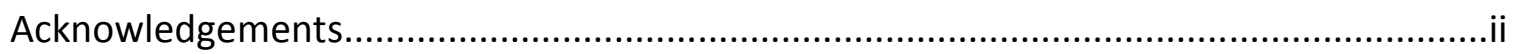

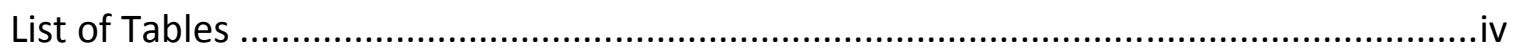

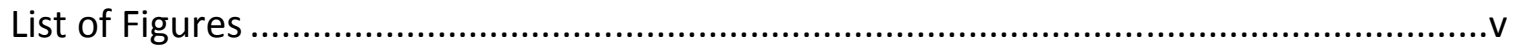

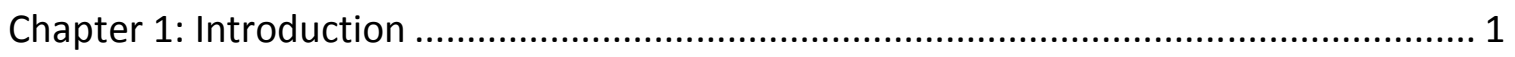

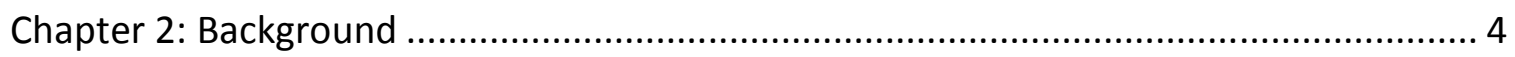

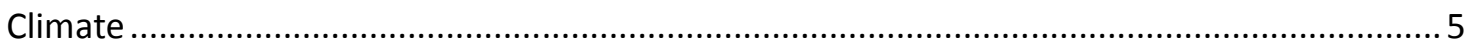

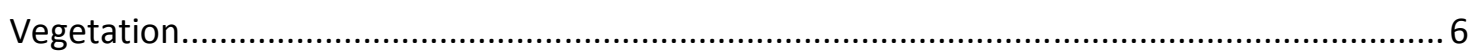

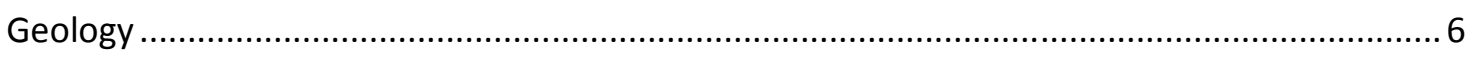

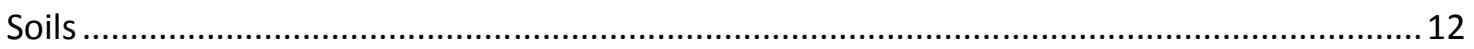

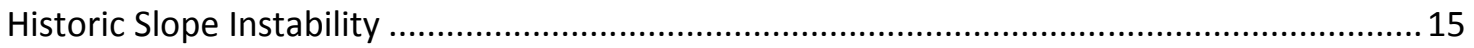

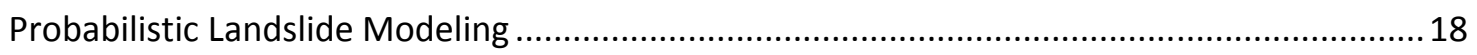

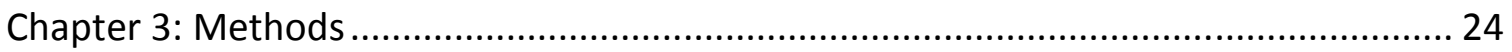

Data Collection, Geographic Information System (GIS) processing, and statistical analysis..... 24

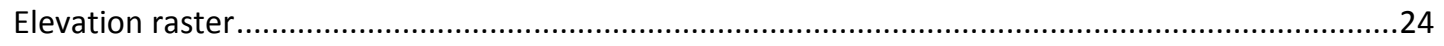

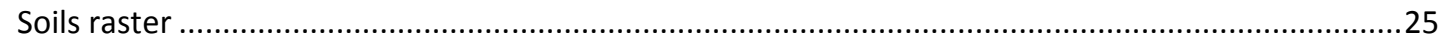

Vegetation raster

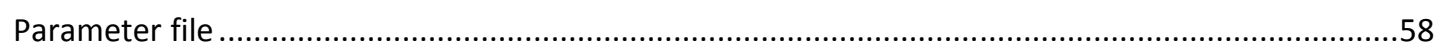

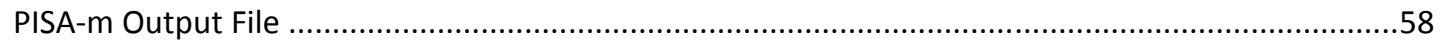

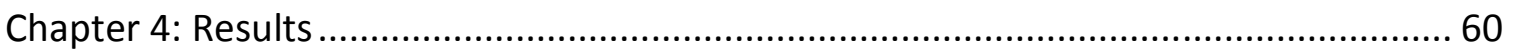

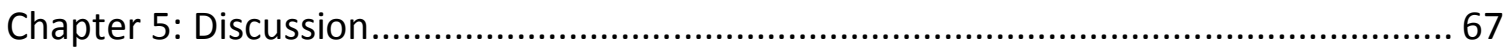

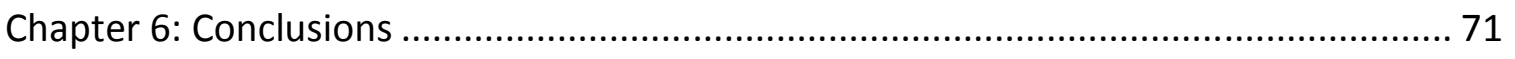

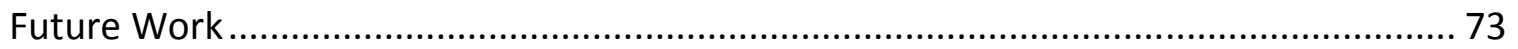

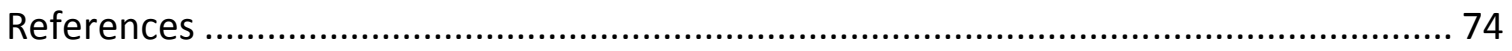

Appendix A: Example of a geotechnical report from BES Public Works Database .......... 77

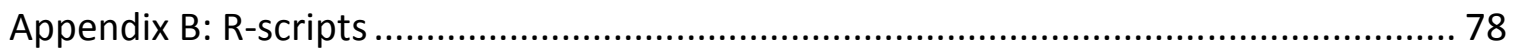

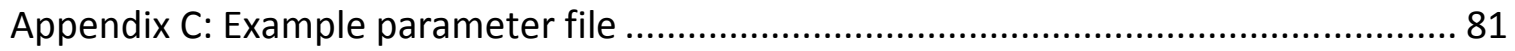




\section{List of Tables}

Table 1. Breakdown of percentage of spatial extent by soil type within the watershed. Note that the overwhelming majority of the soils within the watershed are the Cascade Urban Land Complex (Green, 1983).

Table 2. Number and percentage of landslides by soil type for both the Portland Basin Region and the Stephens Creek Watershed (from Burns, 1996). Note that the overwhelming majority of landslides within the watershed occurred in the Cascade Urban Land Complex. ....................................................................... 18

Table 3. Summary statistics generated from Public Works database.............................. 28

Table 4. General form of an ANOVA table, modified from Davis (2002). ....................... 32

Table 5. Results of a one-way ANOVA of the moist unit weight of the five soil types

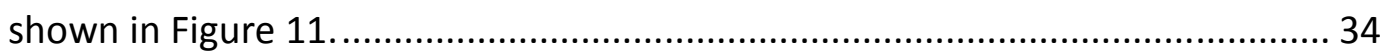

Table 6. Results of F-tests conducted between various soil samples based on their moist unit weight. For all tests, $\alpha=0.05$, and $\mathrm{F}$ and $\mathrm{R}$ in the table refer to reject or failure to reject the null hypothesis, respectively.

Table 7. Results of t-tests conducted between various soil samples based on their moist unit weight. For all tests, $\alpha=0.05$, and $\mathrm{F}$ and $\mathrm{R}$ in the table refer to reject or failure to reject the null hypothesis, respectively. Additionally, superscript w's and d's indicate that t-test used were those described by Wuensch (2010) and Davis (2002), respectively.

Table 8. Table showing the final soil types used in the slope stability analysis of the watershed after combing soil units into two groups based on results of statistical testing, and excluding two soils due to insufficient data.

Table 9. Result of various $\chi 2$ tests comparing soils variables against a normal PDF. .... 48

Table 10. Final distributions and parameters used in soil parameter file...................... 51 


\section{List of Figures}

Figure 1. Small scale map showing the location of the study area within the Portland Metro area.

Figure 2. Larger scale topographic map showing the location of the study area. Note that the majority of the watershed is heavily urbanized. 5

Figure 3. LiDAR image showing the location of various features of the Boring Volcanic Field as wells as flow directions and geomorphic features associated with the Missoula Floods. Image from Allen et al., 2009.

Figure 4. Geology of the Stephens Creek Watershed; map generated with data from

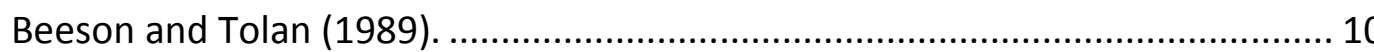

Figure 5. Geologic cross section from Beeson and Tolan (1989). Cross section is N62 $\mathrm{W}$ in the direction from $B-B^{\prime}$, and is approximately 2.7 kilometers due south of the southern boundary of the Stephens Creek Watershed.

Figure 6. Map showing the distribution of soils in the watershed. Note that the majority of soils in within the watershed are urban land complexes. The map was generated with data from Green (1983).

Figure 7. Textural boundaries encompassing 95\% of all Portland Hills Silts (from Lentz, 1981).

Figure 8. Landslide points from February 1996 storm (Burns, 1996) denoted by an " $x$ ", and ancient landslide polygons (modified from Burns and Duplantis, 2010) represented by red and yellow polygons.

Figure 9. Graphical representation of the infinite slope equation given by Eq. 1 (figure from Hammond et al., 1992).

Figure 10. Map showing the entirety of the BES Public Works Database along with boreholes that were spatially correlated with soil types found within the Stephens Creek Watershed.

Figure 11. Box and whisker plot illustrating the variability of moist unit weights between soils (from data given in Table 3). 29 
Figure 12. Final soils raster used in this analysis (areas shaded grey on the map are areas that were not considered in this analysis due to the fact that the soil type in those areas did not occur in the Stephens Creek Watershed). 40

Figure 13. Histograms of PHS geotechnical data with a normal PDF for reference. Note that phi values for the PHS unit do not include a histogram as these data were derived from Drazba (2008) ................................................................... 42

Figure 14. Histograms of URB geotechnical data with a normal PDF for reference. ....... 43

Figure 15. Density plots of PHS geotechnical data with a normal PDF (dashed line) for reference. Note that phi values for the PHS unit do not include a density plot as these data were derived from Drazba (2008).

Figure 16. Density plots of URB geotechnical data with a normal PDF (dashed line) for reference

Figure 17. Final probability distributions for the PHS soil unit used as input into PISA-m. Solid lines are density plots of the data while the dashed lines are PDFs fitted to the data.

Figure 18. Final probability distributions for the URB soil unit used as input into PISA-m. Solid lines are density plots of the data while the dashed lines are PDFs fitted to the data

Figure 19. Sensitivity analysis of variables used in the infinite slope equation (Eq. 1), using values determined in this study.

Figure 20. Comparison of highest hit LiDAR data and high resolution air photos used to delineate forest cover. The red circle in the images shows how air photos were used to verify canopy cover from the LiDAR. In this case, the LiDAR data suggest there are no trees within the red circle. Comparison with the high resolution orthoimagery, however, indicates that trees are indeed present and were subsequently mapped as such. 56

Figure 21. Map showing the final extent of the vegetation raster used in the analysis. . 57 
Figure 22. Histogram showing the percent area of the watershed that is defined by FOS probability bins.

Figure 23. Map of probabilities that the FOS $\leq 1$ for dry, static conditions within the Stephens Creek Watershed.

Figure 24. Map of probabilities that the FOS $\leq 1$ for saturated, static conditions within the Stephens Creek Watershed.

Figure 25. Maps showing probabilities compared to historic and ancient landslides indicating good correlation between modeled probabilities and slope failures. Historic landslide points from February 1996 storm (Burns, 1996), and ancient landslide polygons (modified from Burns and Duplantis, 2010).

Figure 26. Avoidance map, showing areas that should avoid having any water infiltrated into them. The avoidance areas contain sites of historic/ancient landslides, as well as high risk probability areas. 


\section{Chapter 1: Introduction}

The Stephens Creek Watershed basin, located in southwest Portland, Oregon, begins on a ridge just south of the Hillsdale Neighborhood, flows for just over three kilometers, then discharges to the Willamette River just north of the Sellwood Bridge. The drainage area includes 305 hectares of mostly residential neighborhoods, with some commercial areas that include the Burlingame Fred Meyer store and the I-5 corridor. The basin was selected as a pilot project of the Portland Watershed Management Plan (PWMP), which describes the approaches used to evaluate conditions of the City's urban watersheds (City of Portland, 2005). The plan includes the characterization of 27 subwatersheds within the greater Willamette Watershed, in an effort to develop Improvement Strategy (IS) reports that outline projects that would serve to better manage stormwater runoff, protect and improve aquatic and terrestrial habitat, and revegetate natural areas (City of Portland, 2009).

Prior to the development of the IS report, a stream habitat assessment was conducted in 2000 (HARZA, 2000). The assessment determined that habitat located at the mouth of Stephens Creek was one of the most productive areas in the City for salmonid diversity and abundance. The initial IS report, first published in 2005 and updated in 2009, indicates that Stephens Creek suffers from a multitude of factors that contribute to the degradation of overall watershed health. These include but are not limited to, marginal fish habitat, altered stream flow regimes, limited floodplain 
function, decreased channel connectivity, degraded riparian conditions, soil and sediment contamination, bacterial contamination, and a slew of urban storm water pollutants that include heavy metals and nutrients. Considering that Stephens Creek is a critical asset in the preservation of salmonid habitat, mitigation and restoration is of the utmost priority to the City of Portland.

The IS report outlined multiple project opportunities that include stormwater management, outreach, re-vegetation, protection and policy, maintenance, and stream enhancement. A total of 43 stormwater opportunities were listed, including downspout disconnects, eco-roofs, and a variety of infiltration systems of various construction designs (City of Portland, 2009). These opportunities involve managing stormwater on projects that range from individual residential property downspout disconnection, to the construction of stormwater retrofits for large apartment complexes. Given the large total combined surface area of the impervious surfaces outlined in the IS report, there is significant potential to transmit vast quantities of stormwater into the subsurface.

It is well documented that increased soil water content can reduce soil shear strength by decreasing the effective stress of soils (Johnson and DeGraff, 1988). The result of decreased shear strength in response to increased soil water content is well documented within Portland's West Hills (Burns, 1996). There is concern that transmitting large quantities of water into the subsurface, rather than through stormwater infrastructure, could potentially lead to an increased incidence of landslides throughout the basin (Burns, Scott, personal communication 2010). The ability to make 
informed decisions regarding infiltration system placement, therefore, relies on the ability to model the physical response of slopes to in-situ soil pore water conditions within the watershed. The ability to model slope failure processes requires characterizing factors that control it, such as engineering characteristics of soil, in-situ pore water pressures and slope angles. The aims and objectives of this study, therefore, are the characterization, modeling and mapping of the landslide potential of the Stephens Creek Watershed in response to varying hydrologic conditions.

Reaching the aims and objectives of this study required the following steps: 1) compiling engineering properties and spatial distribution of the watershed soils, 2) deriving probability distribution functions (PDFs) for all relevant soil geotechnical variables (which include moist and saturated unit weights, cohesive strength, angle of internal friction, and depth of the soils), 3) calculating probabilities that the factor of safety (FOS) within the watershed was $\leq 1$ by modeling unsaturated soil conditions, 4) calculating probabilities that the factor of safety (FOS) within the watershed was $\leq 1$ by modeling fully saturated soil conditions, and 5) evaluating the feasibility of suggestions from the 2009 IS report regarding stormwater infiltration opportunities. 


\section{Chapter 2: Background}

\section{Study Area}

The Stephens Creek Watershed is located within the Lake Oswego 7.5 minute Quadrangle, in Multnomah County, approximately six kilometers south of downtown Portland (Figure 1). The watershed is approximately 311 hectares and ranges in elevation from 0.76 to 177-m above mean sea level (amsl) (Figure 2).

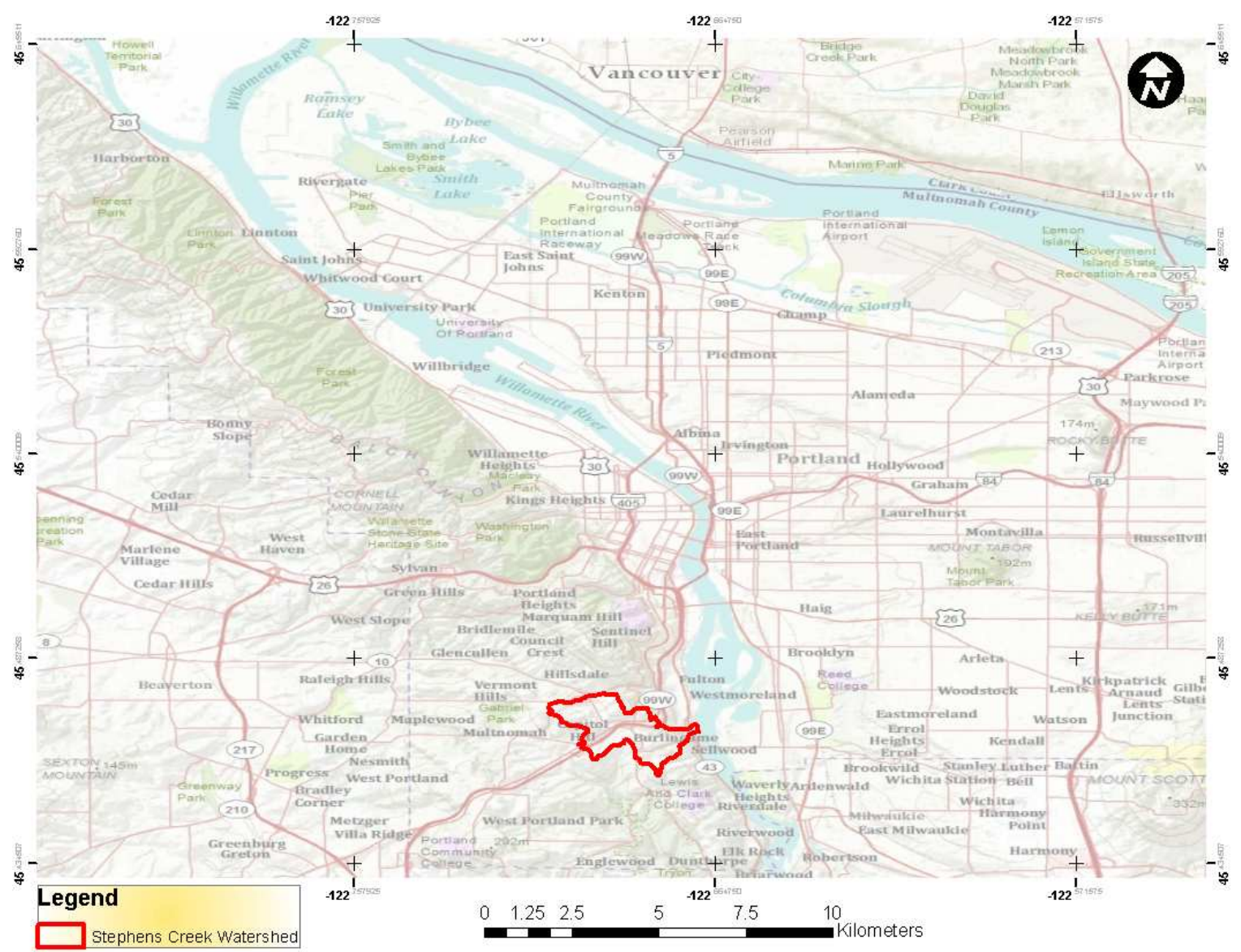

Figure 1. Small scale map showing the location of the study area within the Portland Metro area. 


\section{Climate}

The climate of the watershed is strongly tempered by winds coming off the

Pacific Ocean. Summers are warm, but rarely exceedingly hot, and winters are cool,

ensuring that snow and freezing temperatures are only common in higher elevations

(Green, 1983). Precipitation in the area is frequent in the fall and winter, but infrequent

during the summer, and the average annual rainfall for the region is $92.2 \mathrm{~cm}$ (NOAA,

2009). The average annual high temperature for the Portland region is $17^{\circ} \mathrm{C}$, while the

average annual low temperature is $7^{\circ} \mathrm{C}$ (NOAA, 2009).

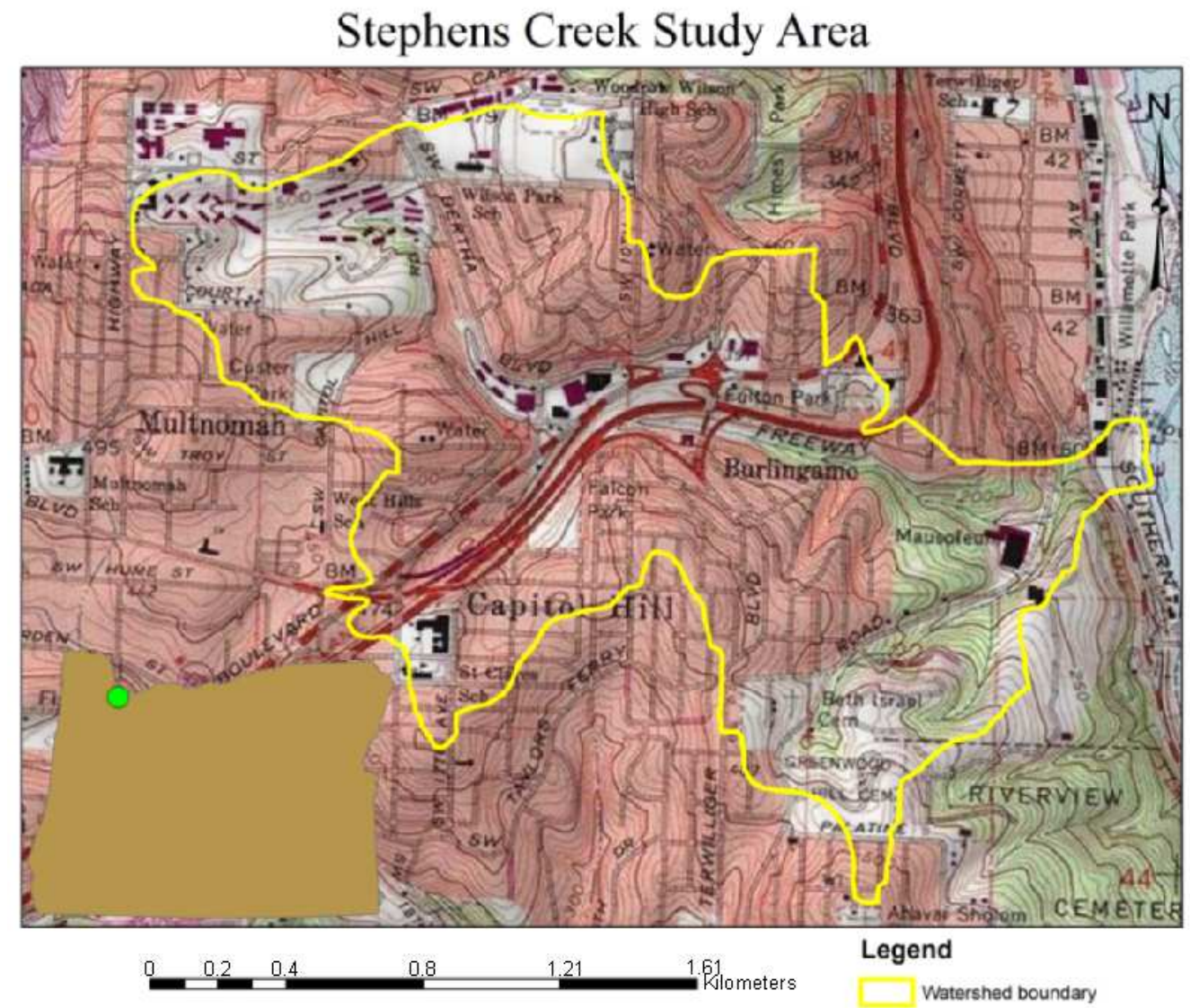

Figure 2. Larger scale topographic map showing the location of the study area. Note that the majority of the watershed is heavily urbanized. 


\section{Vegetation}

The native vegetation of the area consists primarily of Douglas-fir, ash, willow, native apple, and Oregon white oak, although a large portion of the vegetation has been removed due to urban development. In the lower reaches of the watershed, cottonwoods grow along the banks of the Willamette River and can reach heights of up to 24-m (Green, 1983). Additionally, the headwaters of the creek contain a 0.25 -hectare wetland (City of Portland, 2009).

\section{Geology}

Stephens Creek lies on the west-central margin of the Portland Basin, a small Neogene to Holocene basin in the forearc of the Cascadia subduction system (Evarts et al., 2009a). Located near the central portion of the generally north-trending PugetWillamette Trough, the Portland Basin is essentially an elongate, northwest trending bowl. Its structure has been shown to be comprised of a faulted, asymmetric syncline (Evarts et al., 2009a). The basin is bounded on the southwest by the Paleogene Portland Hills, the Pliocene-Pleistocene Boring Lava Field to the southeast, Paleogene volcanic arc rocks of the Cascade Range to the northeast, and is filled with both Miocene-Pleistocene deposits of the ancestral Columbia River as well as the Holocene age cataclysmic Missoula Flood deposits. The history of the Portland Basin from its formation to present day is complex and rich in detail.

According to Evarts et al. (2009a), the Portland Basin began roughly $20 \mathrm{Ma}$ as a broad syncline parallel to the Portland Hills anticline. At 16-15 Ma, massive flood basalts 
of the Columbia River Basalt Group (CRB) flowed down the ancestral Columbia River and formed the backbone of what would become the Portland Hills. The Portland Hills were continuously uplifted throughout the emplacement of the CRB, and by $14 \mathrm{Ma}$, had been established as a permanent structure that would divert the Columbia River northward to its present course within the basin (Evarts et al., 2009)a. From roughly 15-2 Ma, as the basin subsided, the Columbia River continuously deposited sedimentary units that include the middle-Miocene to late-Pliocene Sandy River Mudstone, the middleMiocene volcaniclastic Rhododendron Formation, and various members of the lateMiocene to late-Pliocene Troutdale Formation (Evarts et al., 2009a).

The present topography of the basin owes its morphology to volcanism and the indirect effects of Quaternary glaciation (Evarts et al., 2009a). At the end of the Pliocene, the basin experienced widespread volcanism of the Boring Lava Field within its southeastern half (Figure 3). Beginning as early as $2.6 \mathrm{Ma}$, and continuing to roughly 55 Ka (Evarts et al., 2009b), the field consists of up to 80 cinder cones, lava flows, shields, and lava cones that dot the Portland skyline up to roughly $200 \mathrm{~m}$ amsl. The lavas are composed of predominantly basalt and basaltic andesite (Evarts et al., 2009b).

A vast majority of the basin below roughly $122 \mathrm{~m}$ amsl is buried by the cataclysmic late Pleistocene Missoula Floods (Evarts et al., 2009a). Beginning 18,000 calendar years B.P., a lobe of the Cordilleran ice sheet blocked the Clark Fork River in northwestern Montana, and subsequently created Glacial Lake Missoula, a massive lake with a volume of roughly $2,200 \mathrm{~km}^{3}$, and depth of roughly $520 \mathrm{~m}$ (Allen et al., 2009). 


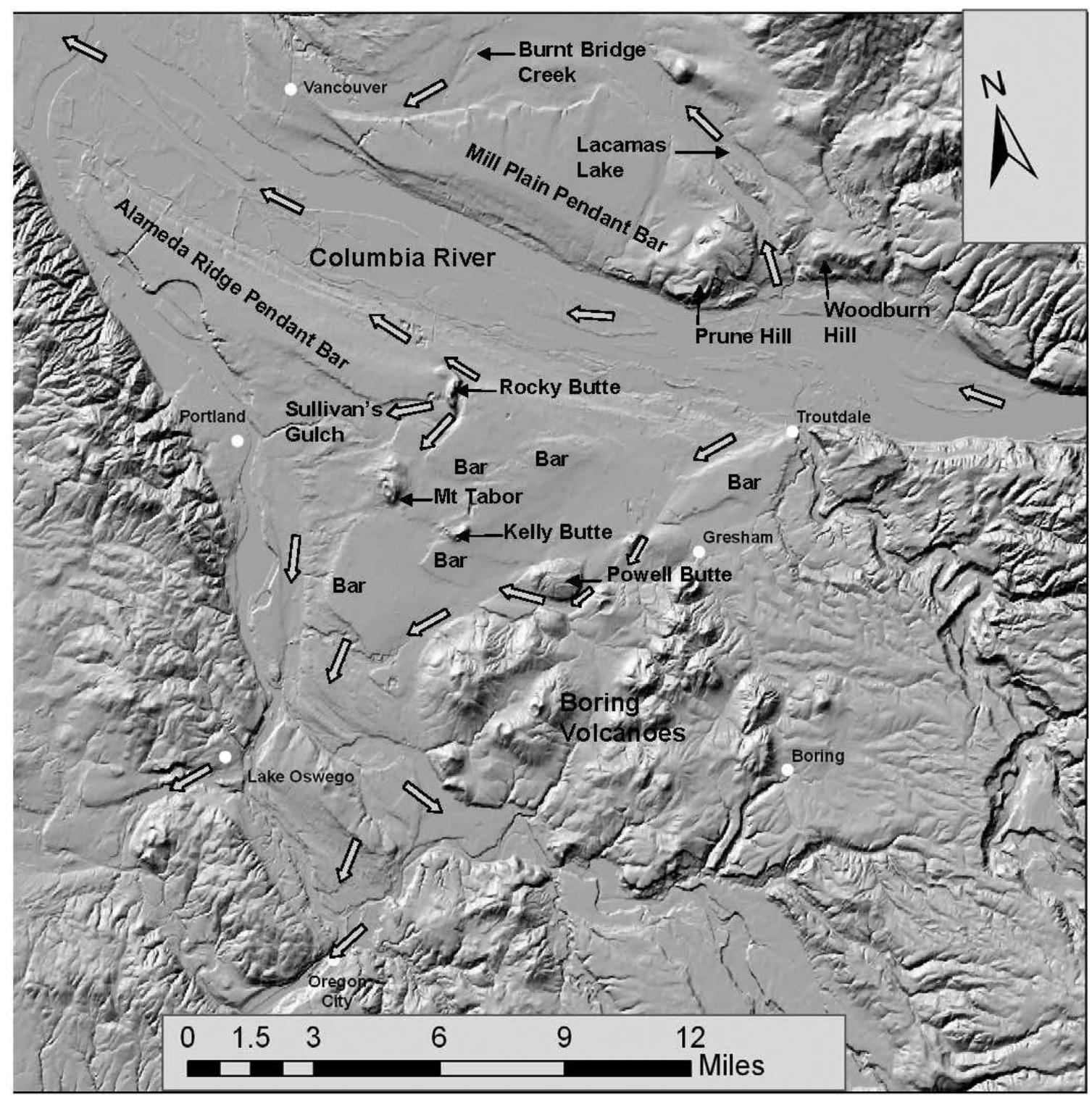

Figure 3. LiDAR image showing the location of various features of the Boring Volcanic Field as wells as flow directions and geomorphic features associated with the Missoula Floods. Image from Allen et al., 2009.

Between 18,000 and 15,000 calendar years B.P., the ice sheet lobe repeatedly advanced and failed, sending a torrent of flood waters throughout eastern Washington, the Columbia River Gorge, and into the Willamette Valley and Portland Basin. The floods carved large channels and deposited massive bars throughout the basin (Figure 3). 
Much of the basin remains buried by flood deposits that consist of silt, sand, gravel, cobbles, and boulders up to nearly $5 \mathrm{~m}$ in diameter (Evarts et al., 2009a).

Above the roughly $122 \mathrm{~m}$ amsl maximum stage of the Missoula Floods, a massive, micaceous, quartzofeldspathic eolian silt blankets the majority of the basin and is known as the Portland Hills Silt (Lentz, 1981). Lawes (1997) describes the silts as being deposited by easterly wind and being derived from fluvial deposits of the Columbia River during the Quaternary.

Within the Stephens Creek Watershed, the geology (Figure 4) is dominated in the west by Pliocene to Holocene undifferentiated sediments (Qts) and is composed mainly of Portland Hills Silt (Beeson and Tolan, 1989). The eastern half of the basin is composed almost entirely of basalts that include members of the middle Miocene Wanapum Basalt (Tfsh, and Tfg), middle Miocene Grande Ronde Basalt (Tgsb), and Eocene Basalts of Waverly Heights (Twh). Other units include fine-grained facies of the Missoula Floods (Qff), and Quaternary alluvium (Qal) that occur along the Willamette River floodplain. Although Beeson and Tolan indicate basalts dominating the eastern half, it should be noted that the bedrock within the watershed is completely covered by Portland Hills Silt of varying depths. 


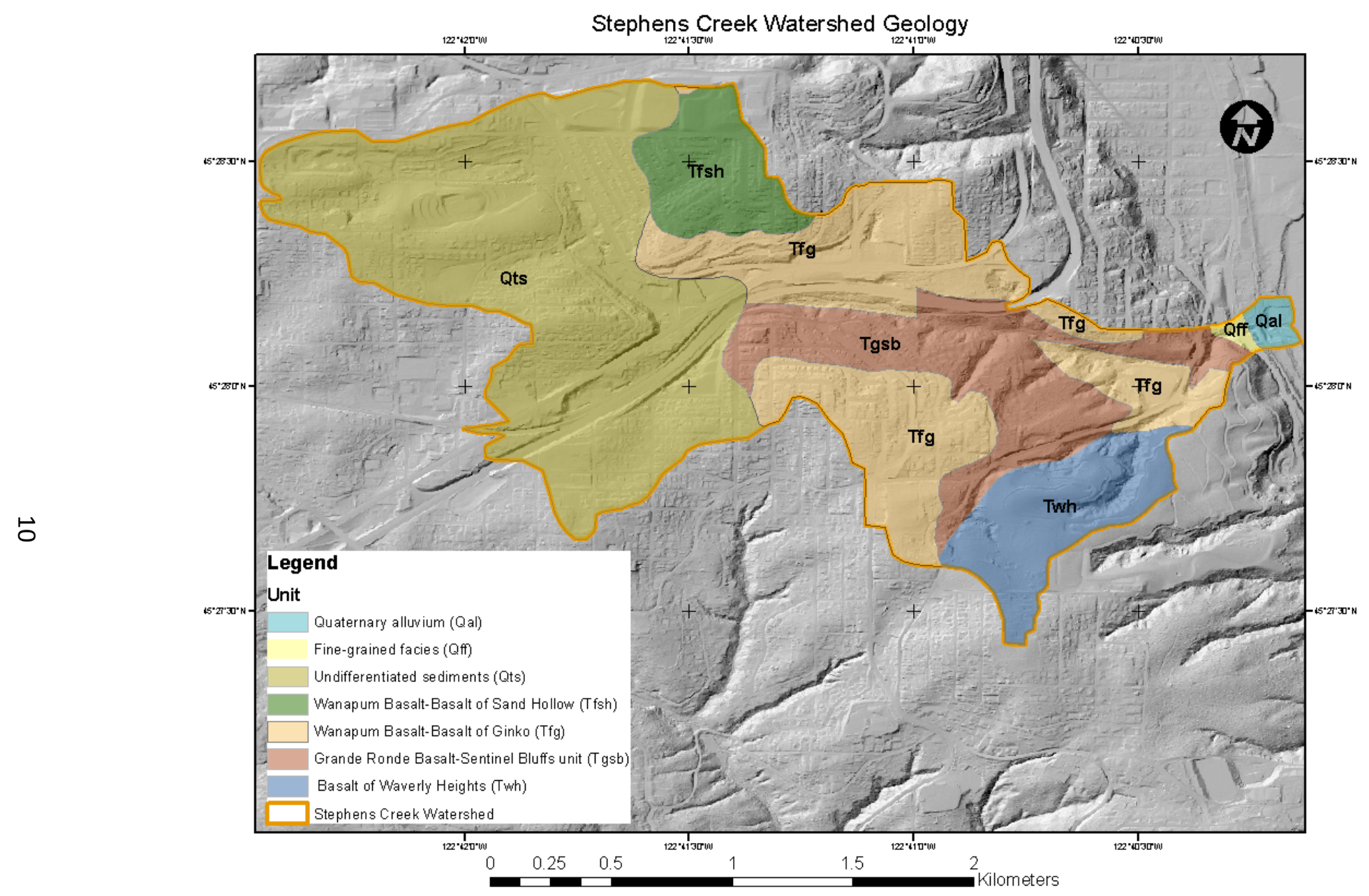

Figure 4. Geology of the Stephens Creek Watershed; map generated with data from Beeson and Tolan (1989). 


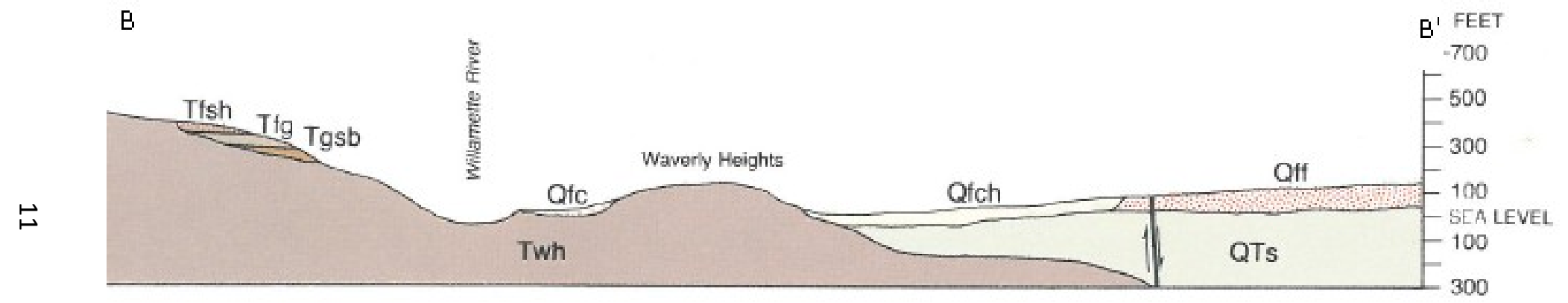

Figure 5. Geologic cross section from Beeson and Tolan (1989). Cross section is N62 ${ }^{\circ} \mathrm{W}$ in the direction from B-B', and is approximately 2.7 kilometers due south of the southern boundary of the Stephens Creek Watershed. 


\section{Soils}

Beeson and Tolan (1989) describe the structure of the Portland Basin within the Lake Oswego 7.5' Quadrangle which contains the Stephens Creek Watershed. Geologic cross sections developed by the authors, indicate (as expected) the broad, faulted Portland Hills as an anticline being composed of the various flows of the CRB overlain by the Portland Hills Silt. The authors also indicate that east of the axis of the anticline, where the entire Stephens Creek Watershed resides, the CRB overly the northeasterly inclined (roughly $30^{\circ}$ ) Basalt of Waverly Heights (Figure 5).

Green (1983) indicates that soils within the watershed consist of somewhat poorly-drained silt loam of the Cascade series, poorly-drained silt loam of the Delena series, steep and moderately-drained silt of the Goble series, very deep and poorly drained Sauvie soils, and various urban land complexes (Figure 6). The Cascade series is of particular note, as it contains a fragipan (dense silt layer) that reduces infiltration and has the potential to act as a failure plain for small landslides (Burns et al., 2006). Although Green indicates nine separate soil types occurring within the watershed, the overwhelming majority of the soils within the watershed consist of the various series of the Cascade Urban Land Complex (Table 1), which is considered to be one contiguous soil unit (as they are differentiated only on the basis of their slope angle). After combining the various Cascade Series soils into one soil unit, seven distinct soil types are indicated within the watershed (Table 1). 


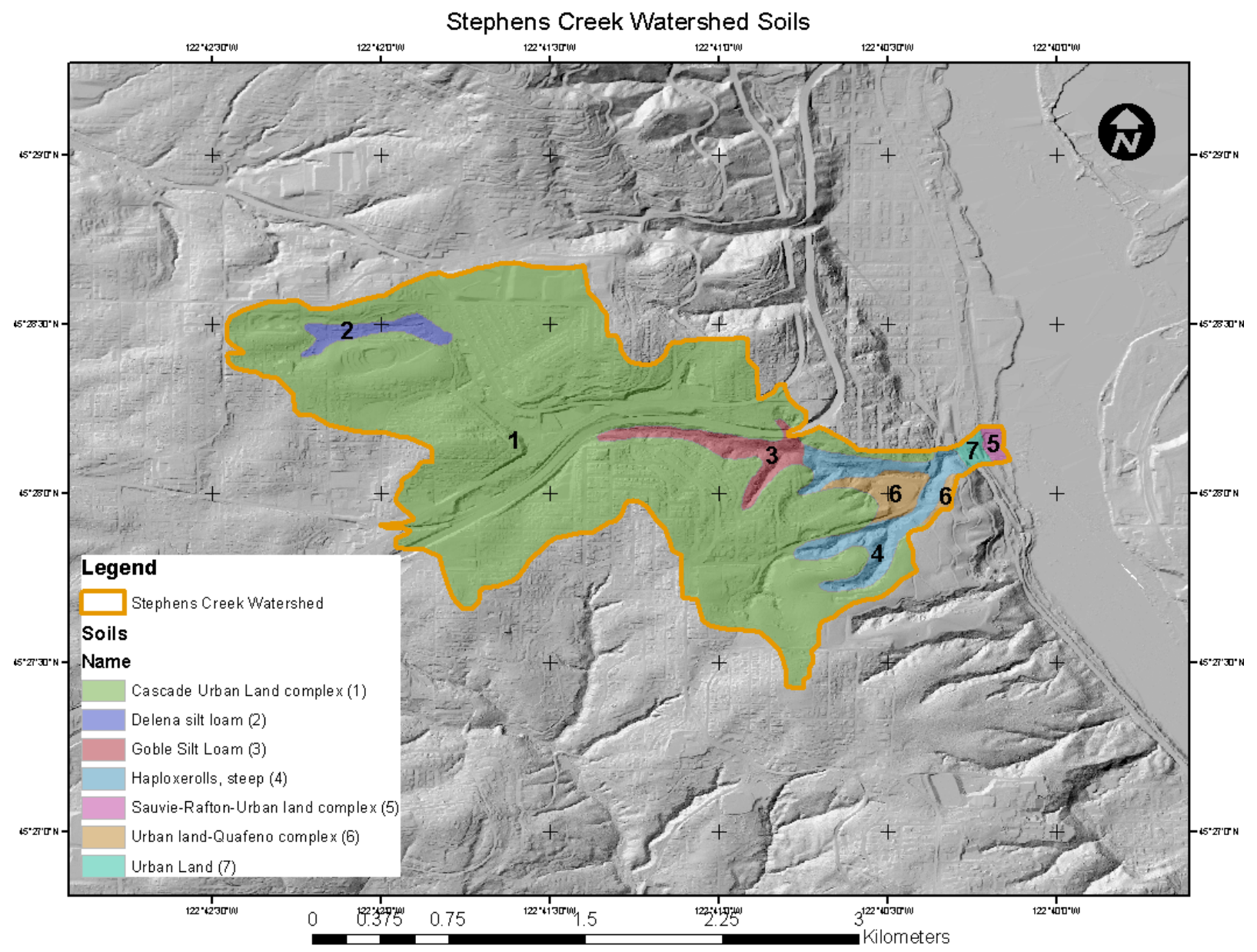

Figure 6. Map showing the distribution of soils in the watershed. Note that the majority of soils in within the watershed are urban land complexes. The map was generated with data from Green (1983). 
Table 1. Breakdown of percentage of spatial extent by soil type within the watershed. Note that the overwhelming majority of the soils within the watershed are the Cascade Urban Land Complex (Green, 1983).

\begin{tabular}{llllllll}
\hline & $\begin{array}{l}\text { Cascade } \\
\text { Urban } \\
\text { Land } \\
\text { Complex }\end{array}$ & $\begin{array}{l}\text { Delena } \\
\text { Silt }\end{array}$ & $\begin{array}{l}\text { Goble } \\
\text { Lilt } \\
\text { Loam }\end{array}$ & $\begin{array}{l}\text { Haploxerolls } \\
\text { (steep) }\end{array}$ & $\begin{array}{l}\text { Sauvie- } \\
\text { Rafton- } \\
\text { Urban } \\
\text { Land } \\
\text { Complex }\end{array}$ & $\begin{array}{l}\text { Urban } \\
\text { Land }\end{array}$ & $\begin{array}{l}\text { Urban } \\
\text { Land- } \\
\text { Quafeno } \\
\text { Complex }\end{array}$ \\
\hline \hline $\begin{array}{l}\text { \% of soil } \\
\text { within } \\
\text { watershed }\end{array}$ & 86.3 & 1.7 & 3.1 & 5.6 & 0.5 & 0.6 & 2.2 \\
\hline
\end{tabular}

Lentz (1981) and Lawes (1997) conducted some of the most comprehensive research to date on the Portland Hills Silt. Lentz showed that the silt is extremely uniform in both texture and composition and has an average grain-size distribution of 5 percent sand, 79 percent silt, and 16 percent clay-sized particles; and a fine-skewed grain-size distribution (Figure 7).

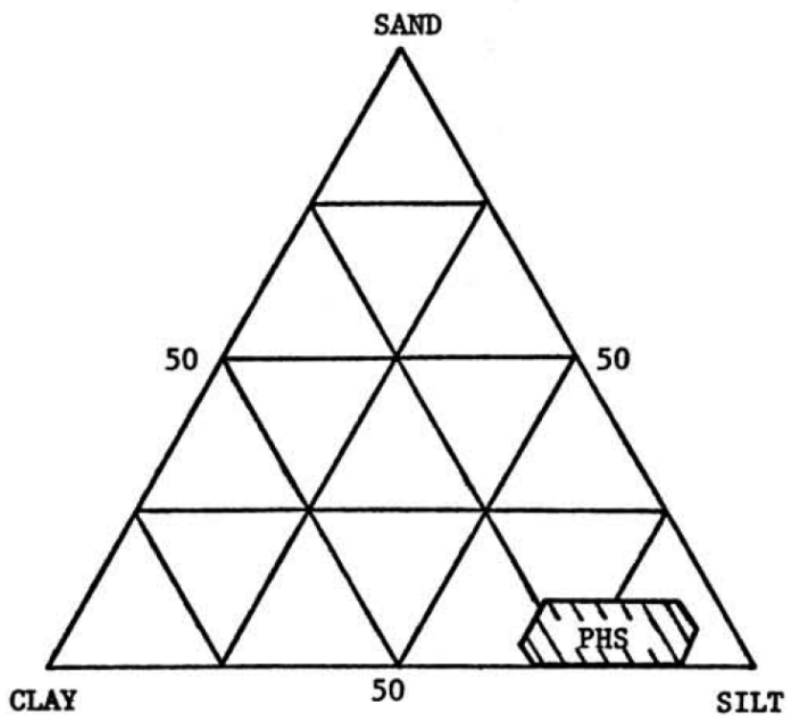

Figure 7. Textural boundaries encompassing $95 \%$ of all Portland Hills Silts (from Lentz, 1981). 
Lawes (1997) also indicated that the silt has a "remarkably uniform" grain size

distribution and reports average sand, silt, and clay grain size percentages of $4.6 \pm 3.3$, $80.9 \pm 4.2$, and $14.9 \pm 5.2$, respectively

Lentz indicated that the silt typically mantles flatter ridge crests and slopes above $150 \mathrm{~m}$ amsl on the eastern flank of the Portland Hills, but locally extends down to 60-90 m amsl on some spurs. It decreases in depth from $37 \mathrm{~m}$ on the eastern slope of the Portland Hills to $15 \mathrm{~m}$ or less on the western slope. Lentz also indicates that deeper exposures of the silt may show up to four thick silt units divided by dark red or brown paleosols, where horizons above the paleosols are commonly mottled and iron-stained, indicating longer periods of water contact and possible barriers to groundwater flow. This was confirmed by Lawes (1997), when he identified four buried soil horizons in a core 26 meter core taken from West $53^{\text {rd }}$ street in Portland's West Hills. Lawes (1997) describes the three uppermost paleosols as "weakly developed" with diffuse contacts, and only moderate mottling. He describes the deepest paleosol as having a "distinctive and immediately recognizable" contact, as well as possessing the highest clay content. Lawes's observations indicate that possibly only the deepest paleosol is well developed enough to act as a barrier to groundwater flow.

\section{Historic Slope Instability}

During an intense precipitation event from February $6^{\text {th }}-9^{\text {th }}, 1996,20 \mathrm{~cm}$ of rain fell over the Portland area. Landslides during this period were so abundant, that the event was determined to be a 100 -year return interval event, climatically, for landslides 
in the region (Burns 1996). Burns and three graduate students mapped 705 landslides in and around the Portland Basin; 374 of which occurred within what Burns refers to as the "West Hills Soil Province", and were primarily earthflows less than 500 cubic $m$ in volume (Burns et al., 2006). Within the Stephens Creek Watershed, 15 landslides occurred in 1996 that ranged from 13 to 421 cubic m (Figure 8) in volume. Mitigation measures employed a multitude of strategies including removal of slide material, construction of retaining walls, and the installation of drainage systems. Total mitigation cost for the 15 slides in the watershed was nearly $\$ 1.25$ million. Burns et al. (1998), noted that 75 percent of the slides in the Portland metro region occurred within three soil types: the Portland Hills silts (48\%), fill (15\%), and the Troutdale Formation (12\%). Additionally, 78 percent of the slides in the Portland metro region were of three physical mechanisms: earthflows (50\%), slump-earthflows $(19 \%)$, or slumps $(9 \%)$, which Burns et al. (1998) attribute to the loess of the West Hills. Within the Stephens Creek Watershed, 93 percent of the 15 landslides that occurred during the 1996 event were within the Cascade Urban-Land complex, with only one additional slide occurring within another soil type (Table 2). 


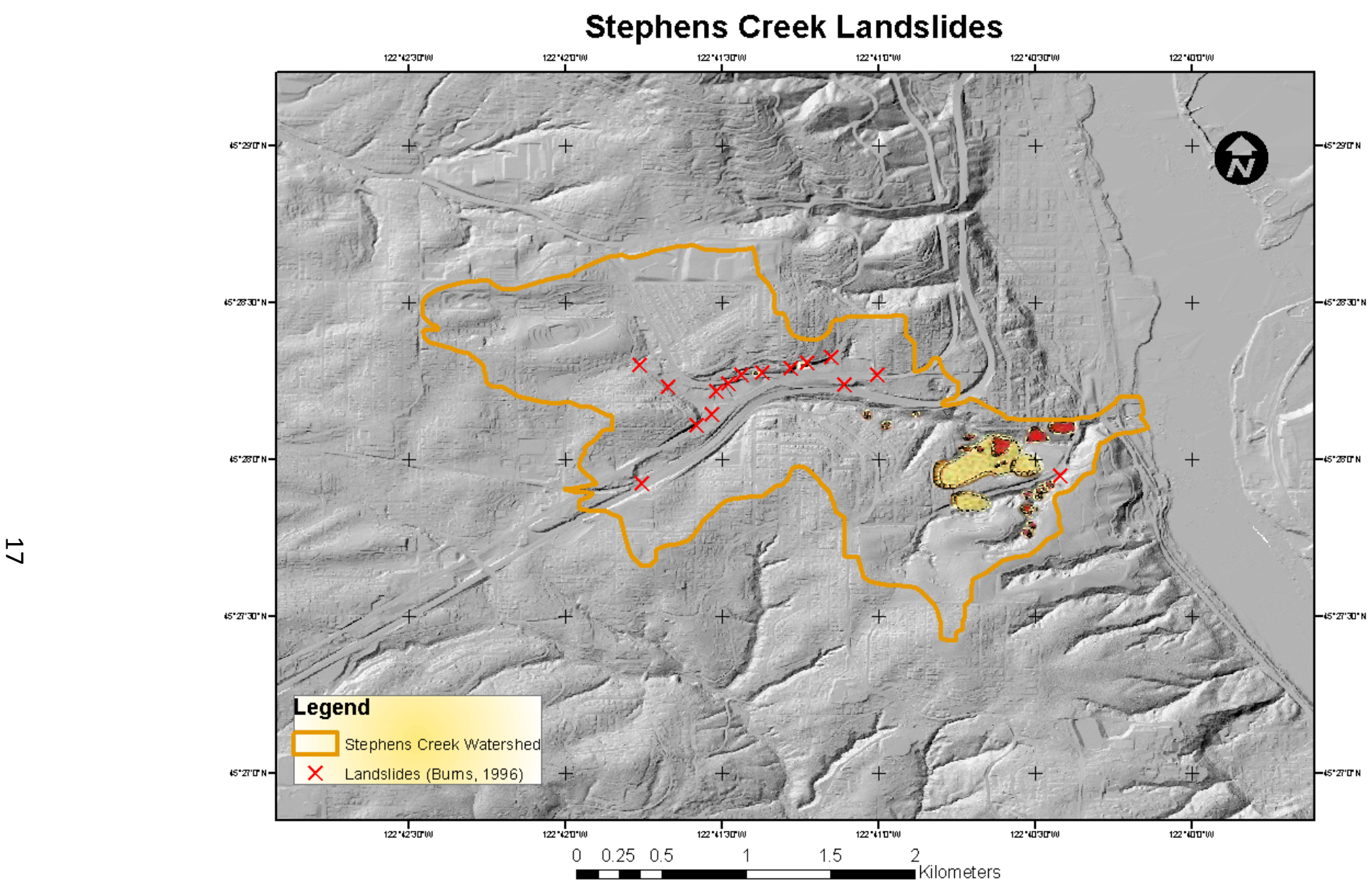

Figure 8. Landslide points from February 1996 storm (Burns, 1996) denoted by an " $x$ ", and ancient landslide polygons (modified from Burns and Duplantis, 2010) represented by red and yellow polygons. 
Table 2. Number and percentage of landslides by soil type for both the Portland Basin Region and the Stephens Creek Watershed (from Burns, 1996). Note that the overwhelming majority of landslides within the watershed occurred in the Cascade Urban Land Complex.

\begin{tabular}{|c|c|c|c|c|c|c|c|}
\hline & $\begin{array}{l}\text { Cascade } \\
\text { Urban } \\
\text { Land } \\
\text { Complex }\end{array}$ & $\begin{array}{l}\text { Delena } \\
\text { Silt } \\
\text { Loam }\end{array}$ & $\begin{array}{l}\text { Goble } \\
\text { Silt } \\
\text { Loam }\end{array}$ & $\begin{array}{l}\text { Haploxerolls } \\
\text { (steep) }\end{array}$ & $\begin{array}{l}\text { Sauvie- } \\
\text { Rafton- } \\
\text { Urban } \\
\text { Land } \\
\text { Complex }\end{array}$ & $\begin{array}{l}\text { Urban } \\
\text { Land }\end{array}$ & $\begin{array}{l}\text { Urban } \\
\text { Land- } \\
\text { Quafeno } \\
\text { Complex }\end{array}$ \\
\hline $\begin{array}{l}\text { Regional } \\
\text { landslides }\end{array}$ & 143 & 2 & 152 & 81 & 0 & 1 & 1 \\
\hline $\begin{array}{l}\text { Regional \% } \\
\text { total }\end{array}$ & 38 & $<1$ & 40 & 21 & 0 & $<1$ & $<1$ \\
\hline $\begin{array}{l}\text { Stephens } \\
\text { landslides }\end{array}$ & 14 & 0 & 0 & 1 & 0 & 0 & 0 \\
\hline $\begin{array}{l}\text { Stephens \% } \\
\text { total }\end{array}$ & 93 & 0 & 0 & 7 & 0 & 0 & 0 \\
\hline
\end{tabular}

\section{Probabilistic Landslide Modeling}

Modeling the failure of slopes often involves the use of rational deterministic models, which are derived from accepted physical principles and properties. Haneberg (2000) defines a deterministic model as "one in which there is an invariant causal relationship between the independent and dependent variables, such that if one knows the independent variables, boundary conditions, and initial conditions accurately, then there is no question as to the outcome". Deterministic models require one value for each independent variable in an equation, and are often average values. The outcome of this type of model is that either an event will occur, or it won't. While this approach has its merits, it assumes that parameters do not vary spatially, and that there is no quantifiable uncertainty associated with the outcome.

Probabilistic models, on the other hand, allow the dependent variables to exhibit a degree of random behavior, so that the occurrence of an event is dependent on 
probabilities. Modeling of landslide potential in this study was employed using the program PISA-m (map-based Probabilistic Infinite Slope Analysis), developed by William C. Haneberg of Haneberg Geoscience. PISA-m is a program that performs probabilistic static and seismic slope stability calculations for topography obtained from LiDAR (Light Detection and Ranging) data (Haneberg, 2007). The program is based on a first-order, second moment (FOSM) formulation of the infinite slope equation used by U.S. Forest Service slope stability programs LISA and DLISA, and can include the effects of tree root strength and tree surcharge. PISA-m is a rational, probabilistic model, meaning that the PISA-m's outcome is based on models derived from well-established physical principles (e.g.: the infinite slope equation) and the probability that an event will occur (which is derived from PDFs of variables in the infinite slope equation). This is in stark contrast to empirically based landslide models (e.g.: rainfall-landslide thresholds), or rational deterministic models that employ average values in place of PDFs. 
The factor of safety (FOS) against sliding for a forested infinite slope (Figure 9;

Hammond et al., 1992) is given as

$$
F O S=\frac{c_{r}+c_{s}+\left[q_{t}+\gamma_{m} D+\left(\gamma_{s a t}-\gamma_{w}-\gamma_{m}\right) H_{w} D\right] \cos ^{2} \beta \tan \phi}{\left[q_{t}+\gamma_{m} D+\left(\gamma_{s a t}-\gamma_{m}\right) H_{w} D\right] \sin \beta \cos \beta}
$$

where

$$
\begin{aligned}
\text { FOS } & =\text { factor of safety (resistive force/driving force) } \\
c_{r} & =\text { cohesive strength contributed by tree roots (force/area) } \\
c_{S} & =\text { cohesive strength of soil (force/area) } \\
q_{t} & =\text { uniform surcharge due to weight of vegetation (force/area) } \\
\gamma_{m} & =\text { unit weight of moist soil above phreatic surface (weight/volume) } \\
\gamma_{s a t} & =\text { unit weight of saturated soil below phreatic surface (weight/volume) } \\
\gamma_{w} & =\text { unit weight of water (9810 } \mathrm{N} / \mathrm{m}^{3} \text { or } 62.4 \mathrm{lb} / \mathrm{ft}^{3} \text { ) } \\
D & =\text { thickness of soil above slip surface } \\
H_{w} & =\text { height of phreatic surface above slip surface, normalized relative to soil } \\
\beta & =\text { thickness (dimensionless) } \\
\phi & =\text { slope angle (degrees) }
\end{aligned}
$$




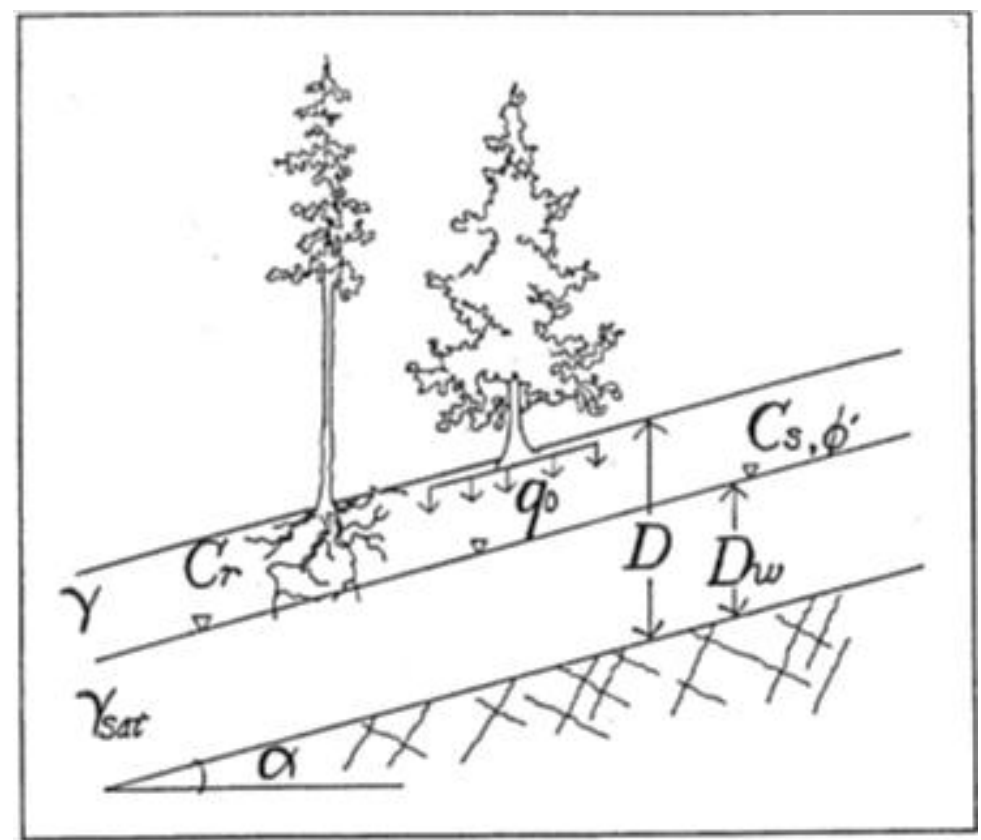

Figure 9. Graphical representation of the infinite slope equation given by Eq. 1 (figure from Hammond et al., 1992).

A mean FOS can be calculated using mean values for all independent variables in Eq. 1. The variance of the dependent variable can then be calculated using the FOSM method (Haneberg, 2000), given by

$$
s_{f}^{2}=\sum_{i}\left(\frac{\partial f}{\partial x}\right)_{x=\bar{x}_{i}}^{2} s_{i}^{2}
$$

where $f=f\left(x_{1}, x_{2}, \ldots x_{N}\right)$ is the dependent variable, $s_{i}^{2}$ is the variance of the $i^{t h}$ independent variable, and $s_{f}^{2}$ is the variance of the dependent variable. Haneberg (2000) explains that the variance of the dependent variable will be the sum of the variances of the independent variables weighted by the square of the sensitivity of the dependent variable to each independent variable. The derivative of Eq. 2 was symbolically and numerically evaluated by Haneberg (2000), using the program 
Mathematica (Wolfram, 1999). Assuming that all independent variables are mutually independent and that there is no model uncertainty, the derivative of Eq. 2 yields the variance of the FS for an infinite slope given by

$$
s_{F S}^{2}=\left[\frac{\rho_{w}}{\rho_{w}^{2}} \frac{H}{D} \frac{\tan \phi^{\prime}}{\tan \beta}\right]^{2} s_{\rho_{s}}^{2}+\left[\frac{\rho_{w}}{\rho_{s}} \frac{\tan \phi^{\prime}}{\tan \beta}\right]^{2} s_{H / D}^{2}+\left[\left(1-\frac{\rho_{w}}{\rho_{s}} \frac{H}{D}\right) \frac{\sec ^{2} \phi^{\prime}}{\tan \beta}\right]^{2} s_{\phi^{\prime}}^{2}+\left[\left(1-\frac{\rho_{w}}{\rho_{s}} \frac{H}{D}\right) \frac{\tan \phi^{\prime}}{\sin ^{2} \beta}\right]^{2} \quad \text { Eq. } 3
$$

Terms in square brackets are evaluated using mean values for each variable. Knowing the mean and variance of all independent variables, and assuming that there are no model errors, an accurate first order estimate of the mean and variance of the FS can be made (Haneberg, 2000).

PISA-m uses input files that contain data (in map form) required to determine FS probabilities for each cell in a LiDAR raster. These input files consist of the LiDAR raster, a soil unit map, and a forest cover map. The LiDAR raster consists of elevation values, while the soil and forest cover map files consist of integer values that reference a parameter file. The parameter file contains the statistical distributions of the geotechnical variables for each soil and forest cover unit. PISA-m reads the input files and produces a map that for each cell in the raster, gives a probability that the slope has a FOS $\leq 1$

In addition to the factors discussed above that affect slope stability, seismic events also have the potential to trigger landslides. PISA-m has the ability to take into account seismic considerations using either Newmark critical acceleration or Newmark displacement using Jibson's simplified method (Haneberg, 2007). The focus of this study, 
however, is specific to the infiltration of stormwater, and seismic considerations are beyond the scope of this project. 


\section{Chapter 3: Methods}

\section{Data Collection, Geographic Information System (GIS) processing, and statistical analysis}

As discussed previously, PISA-m requires four input files: three map files, which include elevation, soil and vegetation rasters, and one parameter file. LiDAR data from the City of Portland (2008) provided the elevation raster. The soils raster was developed by joining geotechnical data to soil maps developed by the Natural Resources Conservation Service (NRCS). The vegetation map was developed using high resolution orthoimagery (GPS Surveying Inc., 2002) to delineate forest cover that was assumed to be that described by Green (1983).

\section{Elevation raster}

From 2004-2007, multiple agencies and organizations flew LiDAR in and around the Portland Metro tri-county region, resulting in the compilation and publication (City of Portland, 2008) of a 0.91-m resolution digital elevation model (DEM) of all Portland area bare-earth LiDAR returns. In May of 2006, a study of the vertical accuracy of the Puget Sound LiDAR Consortium data used in this study found an average maximum vertical error of approximately $40 \mathrm{~cm}$, with a RMS error of $16.71 \mathrm{~cm}$ (City of Portland, 2008). Haneberg (2007) showed that the elevation error associated with DEMs can have significant effects on calculated values of slope angle and static FOS (i.e., slope angle deviations of $\pm 3^{\circ}$ to $\pm 4^{\circ}$ for a USGS standard 10-m DEM). Since the LiDAR data used in this study are much more accurate than the standard USGS 10-m DEM, it is assumed that slope angle errors should be significantly less than $\pm 3^{\circ}$ to $\pm 4^{\circ}$. 
PISA-m accounts for elevation error standard deviation and incorporates it into the model as slope angle variance. Haneberg (2007) states that mean slope angle at a point $(r, c)$ in a DEM is estimated in PISA-m using the second-order accurate finite difference approximation

$$
\beta_{r, c}=\left[\frac{\sqrt{\left(Z_{r, c+1}-Z_{r, c-1}\right)^{2}+\left(Z_{r+1, c}-Z_{r-1, c}\right)^{2}}}{2 \Delta s}\right]
$$

Eq. 4

where $\beta$ is the slope angle in radians, $Z$ is elevation and $\Delta s$ is the DEM grid spacing. PISA-m assumes that elevation error is uniform throughout the DEM and evaluates slope angle variance at point $(r, c)$ using the FOSM expression

$$
s_{\beta}^{2}=\left[\left(\frac{\partial \beta_{r, c}}{\partial Z_{r+1, c}}\right)^{2}+\left(\frac{\partial \beta_{r, c}}{\partial Z_{r-1, c}}\right)^{2}+\left(\frac{\partial \beta_{r, c}}{\partial Z_{r, c+1}}\right)^{2}+\left(\frac{\partial \beta_{r, c}}{\partial Z_{r, c-1}}\right)^{2}\right]
$$

Evaluation of the derivatives in Eq. 5 yields

$$
s_{\beta}^{2}=\frac{8(\Delta s)^{2} s_{Z}^{2}}{\left[4(\Delta s)^{2}+\left(Z_{r+1, c}-Z_{r-1, c}\right)^{2}+\left(Z_{r, c+1}-Z_{r, c-1}\right)^{2}\right]^{2}}
$$

where the variance has units of radians ${ }^{2}$.

\section{Soils raster}

The first step in the creation of the soil raster required joining borehole and geotechnical data to spatial soil data of the tri-county, Portland-metro area, obtained from Green (1982 \& 1983) and Gerig (1985), that were relevant to and within the 
Stephens Creek Watershed. Geotechnical data required for input into PISA-m were obtained from the City of Portland's Bureau of Environmental Services' Public Works Database. The database consists of over 11,000 individual geotechnical reports and drilling logs that span a period of over 50 years (an example of a geotechnical report used in the data compilation is shown in Appendix A). Once soil types relevant to the Stephens Creek Watershed were determined, the tri-county soils data were merged and subsequently joined to relevant borehole and geotechnical data from the entirety of the Public Works Database. This allowed the relevant data in the database to be isolated and reduced the number of potentially useful reports from over 11,000 to just over 2,400 (Figure 10).

Once potentially relevant reports from the database were identified, review of each report was performed and relevant data were extracted and collated into a new raw data file. 708 individual reports provided engineering data that were relevant to soils within the Stephens Creek Watershed, and summary statistics for those data are shown in Table 3. Inspection of summary statistics presented in Table 3 reveals that the quantity of data collected is lacking among some of the soil types existing within the Stephens Creek Watershed. This is problematic due to the fact that probability distribution functions (PDFs) for each variable in Eq. 3 need to be developed for each soil type that is input into PISA-m. 


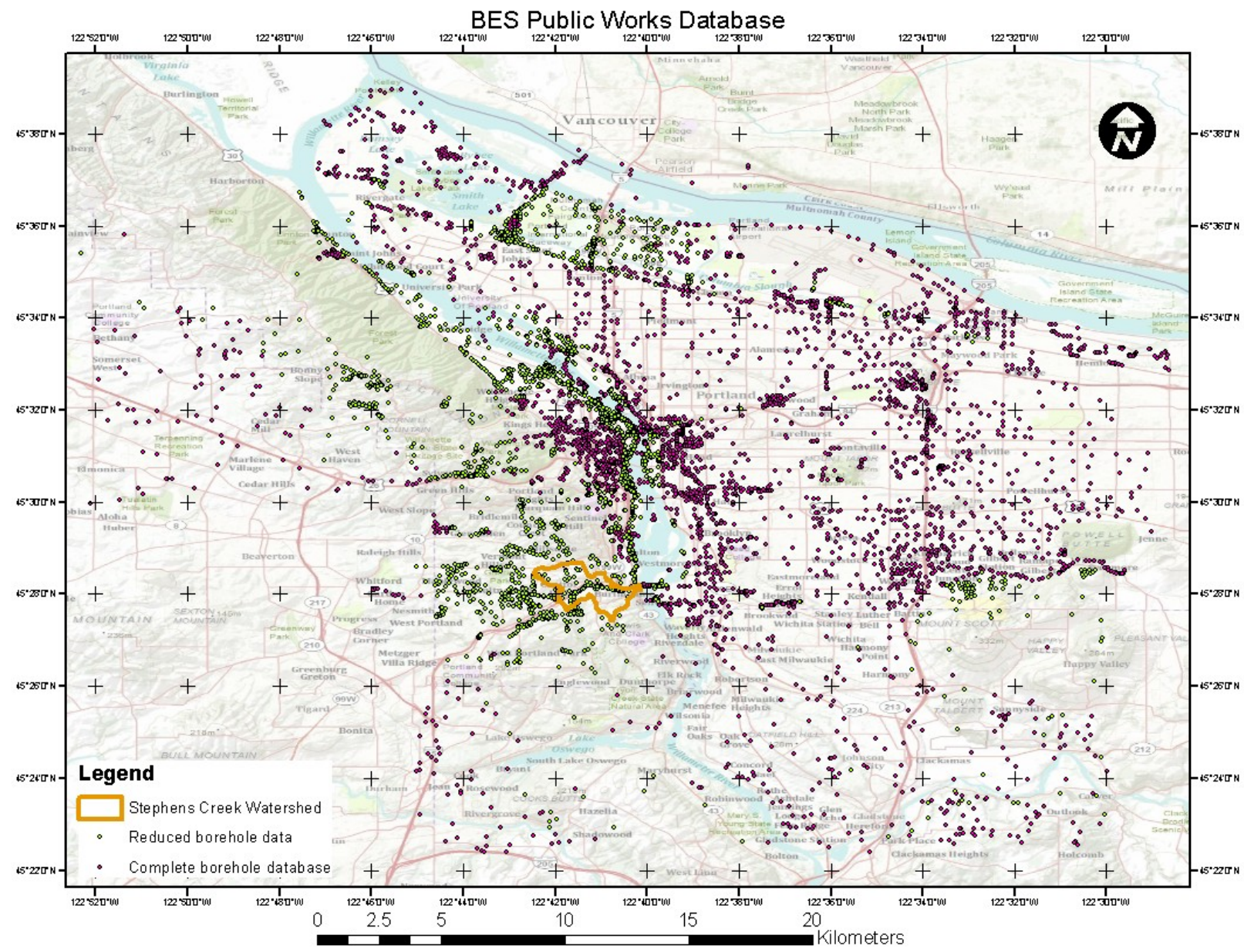

Figure 10. Map showing the entirety of the BES Public Works Database along with boreholes that were spatially correlated with soil types found within the Stephens Creek Watershed. 
Table 3. Summary statistics generated from Public Works database.

\begin{tabular}{|c|c|c|c|c|c|}
\hline & $\begin{array}{c}\text { Slope } \\
\text { Failure } \\
\text { Angle(deg) }\end{array}$ & $\begin{array}{l}\text { Cohesive Strength } \\
\text { (kPa) }\end{array}$ & Depth (m) & $\begin{array}{c}\text { Saturated Unit } \\
\text { Weight } \\
\left(\mathrm{kN} / \mathrm{m}^{\wedge} 3\right)\end{array}$ & $\begin{array}{c}\text { Moist Unit } \\
\text { Weight }\left(k N / m^{\wedge} 3\right)\end{array}$ \\
\hline \multicolumn{6}{|c|}{ SC1-Cascade } \\
\hline Mean & $42^{1}$ & 43.2 & 6.7 & 19.6 & 18.1 \\
\hline Variance & $128^{1}$ & 493.0 & 31.7 & 0.3 & 0.7 \\
\hline St. dev. & $11^{1}$ & 22.2 & 5.6 & 0.5 & 0.8 \\
\hline Number & $147^{1}$ & 32 & 62 & 20 & 37 \\
\hline \multicolumn{6}{|c|}{ SC2-Delena } \\
\hline Mean & $40^{1}$ & $\mathrm{n} / \mathrm{a}$ & 7.8 & $\mathrm{n} / \mathrm{a}$ & $\mathrm{n} / \mathrm{a}$ \\
\hline Variance & $\mathrm{n} / \mathrm{a}$ & $\mathrm{n} / \mathrm{a}$ & 12.7 & $\mathrm{n} / \mathrm{a}$ & $\mathrm{n} / \mathrm{a}$ \\
\hline St. dev. & $\mathrm{n} / \mathrm{a}$ & $\mathrm{n} / \mathrm{a}$ & 3.6 & $\mathrm{n} / \mathrm{a}$ & $\mathrm{n} / \mathrm{a}$ \\
\hline Number & $2^{1}$ & $\mathrm{n} / \mathrm{a}$ & 4 & $\mathrm{n} / \mathrm{a}$ & $\mathrm{n} / \mathrm{a}$ \\
\hline \multicolumn{6}{|c|}{ SC3-Goble } \\
\hline Mean & $41^{1}$ & 38.0 & 7.1 & $\mathrm{n} / \mathrm{a}$ & 18.7 \\
\hline Variance & $129^{1}$ & 362 & 23.2 & $\mathrm{n} / \mathrm{a}$ & 0.4 \\
\hline St. dev. & $11^{1}$ & 19.0 & 4.8 & $\mathrm{n} / \mathrm{a}$ & 0.7 \\
\hline Number & $147^{1}$ & 14 & 30 & $\mathrm{n} / \mathrm{a}$ & 14 \\
\hline \multicolumn{6}{|c|}{ SC4-Haploxerolls } \\
\hline Mean & $45^{1}$ & $n / a$ & 13.3 & $\mathrm{n} / \mathrm{a}$ & 19.8 \\
\hline Variance & $141^{1}$ & $\mathrm{n} / \mathrm{a}$ & 130.6 & $\mathrm{n} / \mathrm{a}$ & 0.3 \\
\hline St. dev. & $12^{1}$ & $\mathrm{n} / \mathrm{a}$ & 11.4 & $\mathrm{n} / \mathrm{a}$ & 0.5 \\
\hline Number & $81^{1}$ & $\mathrm{n} / \mathrm{a}$ & 6 & $\mathrm{n} / \mathrm{a}$ & 4 \\
\hline \multicolumn{6}{|c|}{ SC5-Sauvie } \\
\hline Mean & 33 & 39.0 & 9.1 & 20.3 & 17.2 \\
\hline Variance & $\mathrm{n} / \mathrm{a}$ & 727.6 & 6.1 & 4.8 & 2.2 \\
\hline St. dev. & $\mathrm{n} / \mathrm{a}$ & 27.0 & 2.5 & 2.2 & 1.5 \\
\hline Number & 1 & 9 & 2 & 17 & 27 \\
\hline \multicolumn{6}{|c|}{ SC6-Quafeno } \\
\hline Mean & $85^{1}$ & 135.6 & 10.1 & $\mathrm{n} / \mathrm{a}$ & 19.0 \\
\hline Variance & $\mathrm{n} / \mathrm{a}$ & $\mathrm{n} / \mathrm{a}$ & $\mathrm{n} / \mathrm{a}$ & $\mathrm{n} / \mathrm{a}$ & $\mathrm{n} / \mathrm{a}$ \\
\hline St. dev. & $\mathrm{n} / \mathrm{a}$ & $\mathrm{n} / \mathrm{a}$ & $\mathrm{n} / \mathrm{a}$ & $\mathrm{n} / \mathrm{a}$ & $\mathrm{n} / \mathrm{a}$ \\
\hline Number & $1^{1}$ & 1 & 1 & $\mathrm{n} / \mathrm{a}$ & 1 \\
\hline \multicolumn{6}{|c|}{ SC7-Urban land } \\
\hline Mean & $30^{1}$ & 46.3 & 7.2 & 19.2 & 17.8 \\
\hline Variance & $5^{1}$ & 812.0 & 6.0 & 5.1 & 2.2 \\
\hline St. dev. & $2^{1}$ & 28.5 & 2.5 & 2.3 & 1.5 \\
\hline Number & $21^{1}$ & 20 & 17 & 16 & 13 \\
\hline
\end{tabular}

${ }^{1}$ Data from Burns et al. (1998); all other data from BES public works database

In light of this obstacle, statistical testing was performed using the open-source statistical computing software " $R$ " (R Core Development Team, 2012) to determine whether or not there were any statistically significant differences between the seven 
soil types. This was done in an effort to determine if it was possible to aggregate any of the seven different soil types into fewer categories. Combining soil types into fewer categories allows for both a reduction in work load as well as the ability to have a larger sample sizes; which, according to the central limits theorem (Davis, 2002), increases the tendency for normality of samples. To determine if there were any statistically significant differences amongst the soil samples, a one-way analysis of variance (ANOVA), as well as F and t-tests (as discussed by Davis (2002)) were performed. Only soil types that had sufficient data were tested (i.e., the Delena and Quafeno soils lacked sufficient data for all variables and were excluded from statistical testing).

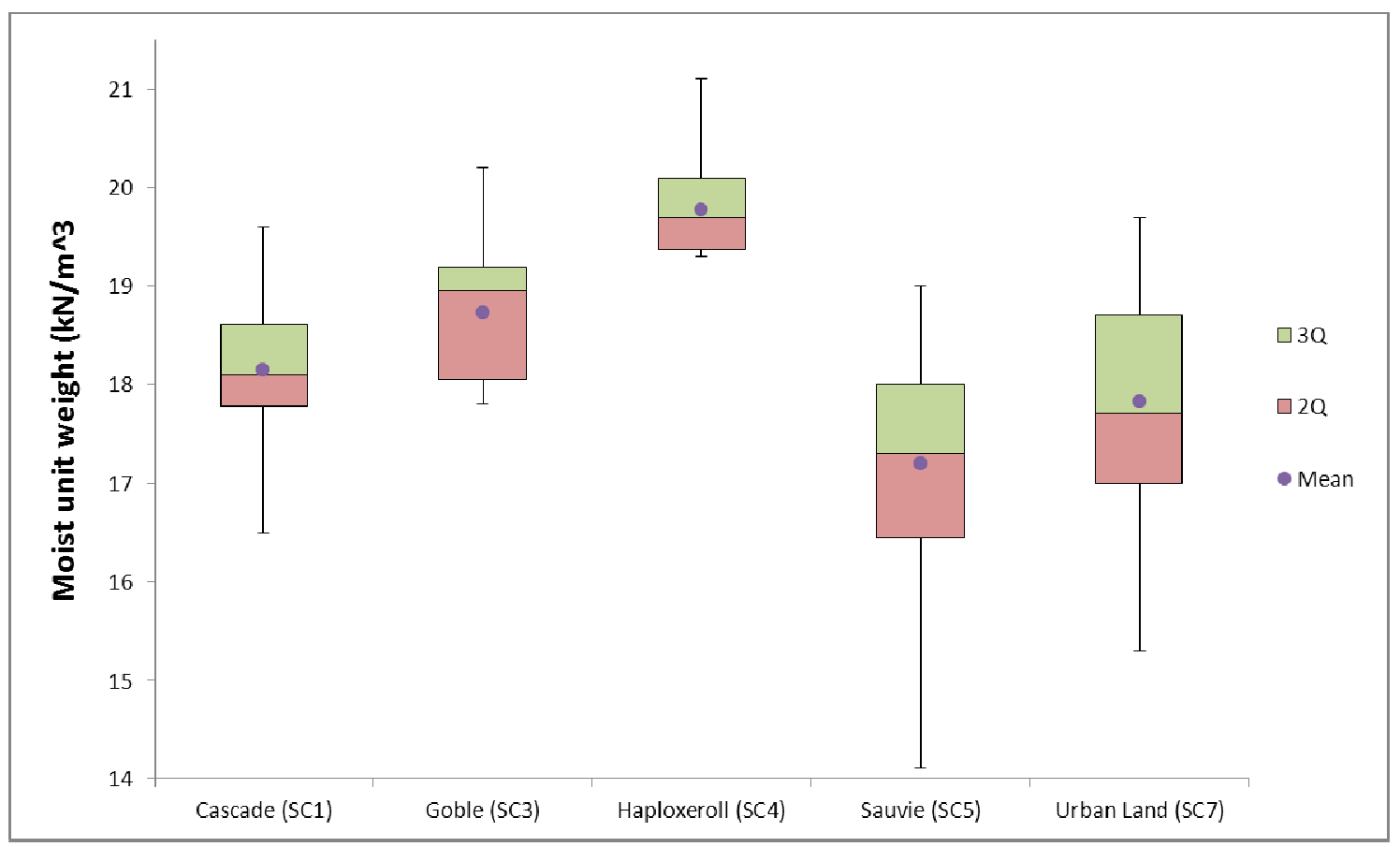

Figure 11. Box and whisker plot illustrating the variability of moist unit weights between soils (from data given in Table 3). 
Only one variable was chosen for statistical testing, and the decision regarding which variable was tested was based largely on sample size as well as consistency with regard to sampling methods. In this study, only the moist unit weight of the five testable soils was chosen for statistical testing (summary statistics describing the variability in the data are shown graphically in Figure 11). This is due to the fact that the moist unit weight variable had the largest sample sizes (with the exception of the Delena and Quafeno soils) as well as the fact that the error associated with sampling methods within samples is likely reduced. Since the five factors that affect soil development (climate, biota, topography, parent material, and time; Birkeland, 1999) are essentially equal for all seven soils within the watershed, coupled with the fact that the geologic constraints on the emplacement of the Portland Hills Silt make this soil widespread and ubiquitous throughout the Stephens Creek Watershed, the variability in moist unit weight as a result of sampling error should be less. The other four engineering variables of the seven soil types are likely to have large sampling error. For example, the angle of internal friction noted in Table 3 was derived from the work done by Burns et al. (1996), where they simply noted the angle of the failure plane within each slope failure. Burns et al. (1996) catalogued all slope failure angles up to $90^{\circ}$, which were actually rockfalls that did not involve the failure of soil on a failure plane. Therefore, this variable has a large error associated with its sampling method. Additionally, the cohesive strength of the soils was determined using many different methods, ranging anywhere from field tests using a pocket penetrometer to laboratory tests using direct shear and Triaxial 
apparatuses. Again, this variable is not well suited for statistical testing due to large error associated with the sampling method. The sampling method used to determine moist unit weight (weighing in the laboratory) was consistent throughout the entirety public works database and should have less sampling error associated with it.

The first step in differentiating the five statistically testable soil samples (those with a sufficient number of observations) was to run a one-way ANOVA (Davis, 2002). Davis states that a one-way ANOVA “involve[s] separating the total variances in a collection of measurements into various components". Wuensch (2010) explains that a one-way ANOVA allows one to perform what he refers to as "protected t-tests", which essentially reduce the probability of making a Type I error. Davis (2002) explains that a Type I error occurs when a null hypothesis, $H_{0}$, is rejected when it is in fact true, and carries a user defined level of significance, $\alpha$, of being erroneous. The end result of a one-way ANOVA is a determination of whether or not means between multiple samples are equal. The test begins (like all statistical tests) by formulating an appropriate null hypothesis, which is an hypothesis of no difference given by

$$
H_{0}: \mu_{1}=\mu_{2}=\mu_{3}=\mu_{n} \quad \text { Eq. } 7
$$

After stating the null hypothesis, an alternative hypothesis is posed, given by

$$
H_{0}: \mu_{1} \neq \mu_{2} \neq \mu_{3} \neq \mu_{n} \quad \text { Eq. } 8
$$

Once the null and alternative hypotheses are stated, a level of significance, $\alpha$, is chosen. The level of significance is the probability, or chance, of committing a Type I error. Once 
the test has been framed in this manner, the test statistic is calculated and compared to a table value from the specified distribution used in the test. If the test statistic falls within the critical region of the distribution, the null hypothesis is rejected, and the alternative hypothesis is accepted. If the null hypothesis cannot be rejected, it is concluded that there is no evidence to support that the samples were drawn from different populations. It is important to note that if the null hypothesis cannot be rejected, it simply means that there is no evidence to suggest that the two samples were drawn from different populations. It does not mean that the samples are in fact from the same population, because this statement carries with it an unknown probability of being incorrect.

The next step in performing the one-way ANOVA was to create an ANOVA table (an example of the general form of an ANOVA table is shown in Table 4).

Table 4. General form of an ANOVA table, modified from Davis (2002).

\begin{tabular}{|c|c|c|c|c|}
\hline Source of variation & $\begin{array}{c}\text { Sum of } \\
\text { squares }\end{array}$ & $\begin{array}{c}\text { Degrees of } \\
\text { freedom }\end{array}$ & Mean squares & F-test \\
\hline Among samples & $S S_{A}$ & $S S_{A}$ & $M S_{A}$ & $M S_{E}$ \\
\hline $\begin{array}{c}\text { Within } \\
\text { observations(error) }\end{array}$ & $S S_{E}$ & $N-m$ & $M S_{E}$ & \\
\hline Total variation & $S S_{T}$ & $N-1$ & & \\
\hline
\end{tabular}

The total variation is given by the total sum of squares, $S S_{T}$, calculated by

$$
S S_{A}=\sum_{j=1}^{m} \sum_{i=1}^{n} x_{i j}^{2}-\frac{\left(\sum_{j=1}^{m} \sum_{i=1}^{n} x_{i j}\right)^{2}}{N}
$$


where $m$ is the number of samples, $n$ is the number of replicates per sample., and $N$ is the total number of observations. The variation among samples, $S S_{A}$, is given by

$$
S S_{A}=\sum_{j=1}^{m} \frac{\left(\sum_{i=1}^{n} x_{i j}\right)^{2}}{n}-\frac{\left(\sum_{j=1}^{m} \sum_{i=1}^{n} x_{i j}\right)^{2}}{N}
$$

The variation within observations, $S S_{E}$, is given by

$$
S S_{E}=\sum_{j=1}^{m} \sum_{i=1}^{n} x_{i j}^{2}-\sum_{j=1}^{m} \frac{\left(\sum_{i=1}^{n} x_{i j}\right)^{2}}{n}
$$

Lastly, the mean squares among samples, $M S_{A}$, and within observations, $M S_{E}$, are calculated by

$$
M S_{A}=\frac{S S_{A}}{m-1}
$$

and

$$
M S_{E}=\frac{S S_{E}}{N-m}
$$

The last step in the one-way ANOVA is to perform an F-test to determine the equality of variances between samples. The F-test is based on a probability distribution called the Fdistribution (Davis, 2002), which is a theoretical distribution of values that would be expected by randomly sampling from a normal population and calculating the ratio

$$
F=\frac{M S_{A}}{M S_{E}}
$$


The results of the one-way ANOVA on the moist unit weight of the five testable soils are given in Table 5. The F-table value for the degrees of freedom listed in Table 5 is equal to 2.5 . Since the F-statistic, 7.5 , is greater than the table value of 2.5 , the null hypothesis is rejected and the alternate hypothesis accepted. This indicates that there is a statistically significant difference between at least two of the sample means.

Table 5. Results of a one-way ANOVA of the moist unit weight of the five soil types shown in Figure 11.

\begin{tabular}{ccccc}
\hline Source of variation & $\begin{array}{c}\text { Sum of } \\
\text { squares }\end{array}$ & $\begin{array}{c}\text { Degrees of } \\
\text { freedom }\end{array}$ & Mean squares & F-test \\
\hline Among samples & 38.1 & 4 & 9.5 & 7.5 \\
\hline $\begin{array}{c}\text { Within } \\
\text { observations(error) }\end{array}$ & 114.0 & 90 & 1.3 & \\
\hline Total variation & 152.2 & 94 & & \\
\hline
\end{tabular}

The next step was to perform F-tests between each sample in order to determine the appropriate t-test to use to differentiate between samples. Wuensch (2010) indicates that for samples of unequal size and homogenous variances the appropriate t-test is given by

$$
t=\frac{\bar{X}_{l}-\bar{X}_{J}}{\sqrt{M S_{E}\left(\frac{1}{n_{i}}+\frac{1}{n_{j}}\right)}}
$$

where $\overline{X_{i}}$ and $\overline{X_{j}}$ are the means of the two samples. Wuensch (2010) goes on to explain that for samples of unequal size and heterogeneous variances, one needs to compute separate variances t-tests with adjusted degrees of freedom. Davis (2002) indicates that the proper t-test to be used in this situation is Welch's t-test given by 


$$
t=\frac{\bar{X}_{l}-\bar{X}_{J}}{s_{\overline{x_{l}}-\overline{x_{J}}}}
$$

where

$$
s_{\overline{x_{l}}-\overline{x_{J}}}=\sqrt{\frac{s_{1}^{2}}{n_{i}}+\frac{s_{2}^{2}}{n_{j}}}
$$

The degrees of freedom for Welch's t-test is calculated using

$$
\text { d. o.f. }=\frac{\left(s_{1}^{2} / n_{1}+s_{2}^{2} / n_{2}\right)^{2}}{\frac{\left(s_{1}^{2} / n_{1}\right)^{2}}{\left(n_{1}-1\right)}+\frac{\left(s_{2}^{2} / n_{2}\right)^{2}}{\left(n_{2}-1\right)}}
$$

Before the appropriate t-tests could be run, F-tests between each of the five samples was performed to determine if the variance between samples were homogenous or heterogeneous using

$$
F=\frac{s_{1}^{2}}{s_{2}^{2}}
$$

where $s_{1}^{2}$ and $s_{2}^{2}$ are the sample variances, and $s^{2}$ is given by

$$
s^{2}=\frac{\sum_{i=1}^{n} x_{i}^{2}-n \bar{X}^{2}}{n-1}
$$

where $x_{i}$ is the $\mathrm{i}^{\text {th }}$ observation, $n$ is the total number of observations, and $\bar{X}$ is the sample mean. Since the F-distribution models the probabilities of obtaining certain 
ratios of sample variances obtained from the same population, an F-test can be used to determine the equality of variances between samples. After calculating the F-statistic given by Eq. 19, the probability of obtaining that specific value for two samples drawn from a normal population can be determined from the F-distribution. If it is statistically unlikely that that the ratio could be obtained, it suggests, with a certain level of significance, that the samples must have come from different populations having different variances.

The test begins by formulating an appropriate null hypothesis, $H_{0}$, which is an hypothesis of no difference given by

$$
H_{0}: s_{1}^{2}=s_{2}^{2}
$$

After stating a null hypothesis, an alternative hypothesis is posed, given by

$$
H_{a}: s_{1}^{2} \neq s_{2}^{2}
$$

F-tests were performed between the five soil samples located within the Stephens Creek Watershed based on their moist unit weight as given in Table 3. All tests were run with the following hypotheses and parameters

$$
\begin{gathered}
H_{0}: s_{1}^{2}=s_{2}^{2} \\
H_{a}: s_{1}^{2} \neq s_{2}^{2} \\
\alpha=0.05
\end{gathered}
$$


Table 6. Results of F-tests conducted between various soil samples based on their moist unit weight. For all tests, $\alpha=0.05$, and $F$ and $R$ in the table refer to reject or failure to reject the null hypothesis, respectively.

\begin{tabular}{cccccc}
\hline \multicolumn{6}{c}{ Moist Unit Weight } \\
\hline \hline Cascade & Cascade & Goble & Haploxeroll & Sauvie & Urban Land \\
Goble & - & - & - & - & - \\
Haploxeroll & $\mathrm{F}$ & - & - & - & - \\
Sauvie & $\mathrm{F}$ & $\mathrm{F}$ & - & - & - \\
Urban Land & $\mathrm{R}$ & $\mathrm{R}$ & $\mathrm{R}$ & - & - \\
\hline
\end{tabular}

The results of the various F-tests are shown in Table 6, and they suggest that there are no statistically significant differences between the variances of the Cascade, Goble, and Haploxeroll soils, as well as between the Urban Land and Sauvie soils. These results dictate which type of t-test is used between each set of samples (the Wuensch for failure to reject (F) results, and Welch's for reject (R) results).

Once it was determined whether variances between samples were homogenous or heterogeneous, t-tests were performed in the same manner as the F-tests described above. As with the F-test, the t-test follows the same process of establishing null and alternative hypotheses, calculating a test statistic, and comparing it to a table value. Hypotheses and parameters for all subsequent t-tests performed here were

$$
\begin{gathered}
H_{0}: \mu_{1}=\mu_{2} \\
H_{a}: \mu_{1} \neq \mu_{2} \\
\alpha=0.05
\end{gathered}
$$


Table 7. Results of t-tests conducted between various soil samples based on their moist unit weight. For all tests, $\alpha=0.05$, and $F$ and $R$ in the table refer to reject or failure to reject the null hypothesis, respectively. Additionally, superscript w's and d's indicate that t-test used were those described by Wuensch (2010) and Davis (2002), respectively.

Moist Unit Weight

\begin{tabular}{cccccc}
\hline \hline & Cascade & Goble & Haploxeroll & Sauvie & Urban Land \\
\hline Cascade & - & - & - & - & - \\
Goble & $F^{w}$ & - & - & - & - \\
Haploxeroll & $F^{w}$ & $F^{w}$ & - & - & - \\
Sauvie & $R^{d}$ & $R^{d}$ & $R^{d}$ & - & - \\
Urban Land & $R^{d}$ & $R^{d}$ & $R^{d}$ & $F^{w}$ & - \\
\hline
\end{tabular}

Results of the various t-tests shown in Table 7 suggest that there are no statistically significant differences between the Cascade, Goble, and Haploxeroll soils, as well as between the Urban Land and Sauvie soils. This means that there are no statistically significant differences between two groups of soil units: 1) the Cascade, Goble, and Haploxeroll soil units, and 2) the Sauvie and Urban Land soil units.

Based on results of the one-way ANOVA, F-tests, and t-tests shown in the above tables, there is no evidence to suggest that soil unit data within each group came from different parent populations. By that rationale, it is assumed that the respective soil units in each group were drawn from the same populations and for analysis purposes have been combined into two soil units. The two combined soil units are referred to from this point forward simply as the "Portland Hills Silt" (PHS; composed of the 
Cascade, Goble, and Haploxeroll soils), and "Urban Lands" (URB; composed of the Sauvie and Urban Land soils) soil units.

Table 8 and Figure 12 show the final soil types that were used in this study. It is important to note that Table 8 only includes two soils after statistical testing resulted in two statistically similar groups of soil units out of the original seven soil types, and a lack of sufficient data excluded two soil units (Delena and Quafeno) from further analysis. The Delena and Quafeno soil units were assigned the same statistics as the URB soil unit and were reclassified in the GIS soil units map for computational simplicity when running PISA-m. The assignment of the Quafeno soil to the URB soil unit is justified by Green (1983), where he describes it as "Urban land - Quafeno complex". Additionally, the five factors affecting soil development are likely to vary little over the small spatial extent of the Quafeno and Urban Land soils within the Stephens Creek Watershed, and the two should therefore be similar in composition and texture (Birkeland, 1999).

It is important to note that phi values shown in Table 3 were not obtained through geotechnical lab tests, but were derived from Burns (1996), where he simply noted slope angle at failure while compiling a field-based landslide inventory. Data obtained from Drazba (2008) provide appropriate phi values for the PHS soil unit. Drazba employed a data mining effort similar to that performed here and obtained phi values from an earlier BES archive. The result of Drazba's research indicated phi values of $27.8^{\circ} \pm 3.8^{\circ}$ for the PHS soil unit, and these values are assumed and used as input parameters for PISA-m. 


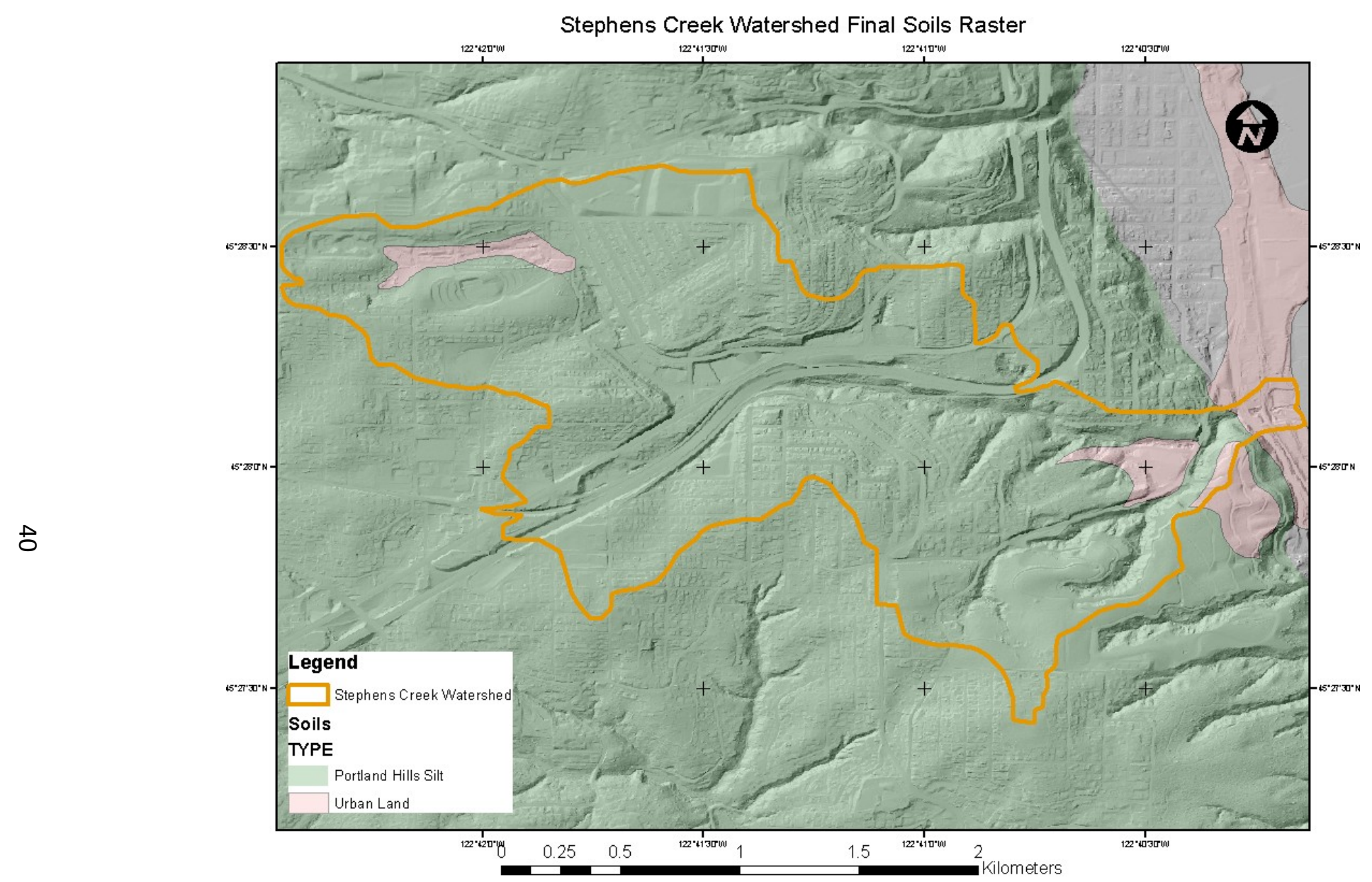

Figure 12. Final soils raster used in this analysis (areas shaded grey on the map are areas that were not considered in this analysis due to the fact that the soil type in those areas did not occur in the Stephens Creek Watershed). 
Table 8. Table showing the final soil types used in the slope stability analysis of the watershed after combing soil units into two groups based on results of statistical testing, and excluding two soils due to insufficient data.

\begin{tabular}{|c|c|c|c|c|c|}
\hline & Phi(degrees) & $\begin{array}{c}\text { Cohesive } \\
\text { Strength }(\mathrm{kPa})\end{array}$ & $\begin{array}{l}\text { Depth } \\
\text { (m) }\end{array}$ & $\begin{array}{c}\text { Saturated Unit } \\
\text { Weight }\left(k N / m^{\wedge} 3\right)\end{array}$ & $\begin{array}{c}\text { Moist Unit } \\
\text { Weight } \\
\left(\mathrm{kN} / \mathrm{m}^{\wedge} 3\right)\end{array}$ \\
\hline \multicolumn{6}{|c|}{ Portland Hills Silt (PHS) } \\
\hline Mean & $27.8^{1}$ & 41.6 & 7.2 & 19.6 & 18.4 \\
\hline Variance & $14.4^{1}$ & 450.0 & 36.1 & 0.3 & 0.8 \\
\hline St. deviation & $3.8^{1}$ & 21.2 & 6.0 & 0.5 & 0.9 \\
\hline Count & $18^{1}$ & 46 & 98 & 20 & 55 \\
\hline \multicolumn{6}{|c|}{ Urban Lands (URB) } \\
\hline Mean & 30 & 44.1 & 7.4 & 19.8 & 17.4 \\
\hline Variance & 5 & 770.8 & 6.0 & 5.1 & 2.3 \\
\hline St. deviation & 2 & 27.8 & 2.5 & 2.3 & 1.5 \\
\hline Count & 22 & 29 & 19 & 33 & 40 \\
\hline
\end{tabular}

${ }^{1}$ Data from Drazba, 2008

The next step in creation of the soils raster required determining proper PDFs for the engineering characteristics of the soil units included in the soil raster. This was required as input to the parameter file used for PISA-m to function properly. In order to make a first approximation as to which PDF each soil variable might best be described by, histograms of each soil variable were plotted with a normal or Poisson PDF for reference as shown in Figure 13 and Figure 14. Inspection of Figure 13 and Figure 14 indicates that although some of the data appear to be normally distributed (moist unit weight for Urban Land soils), others do not (angle of internal friction for Urban Land soils). Density plots of each soil variable were plotted as an additional measure of comparison to the normal PDF and are shown in Figure 15 and Figure 16. 

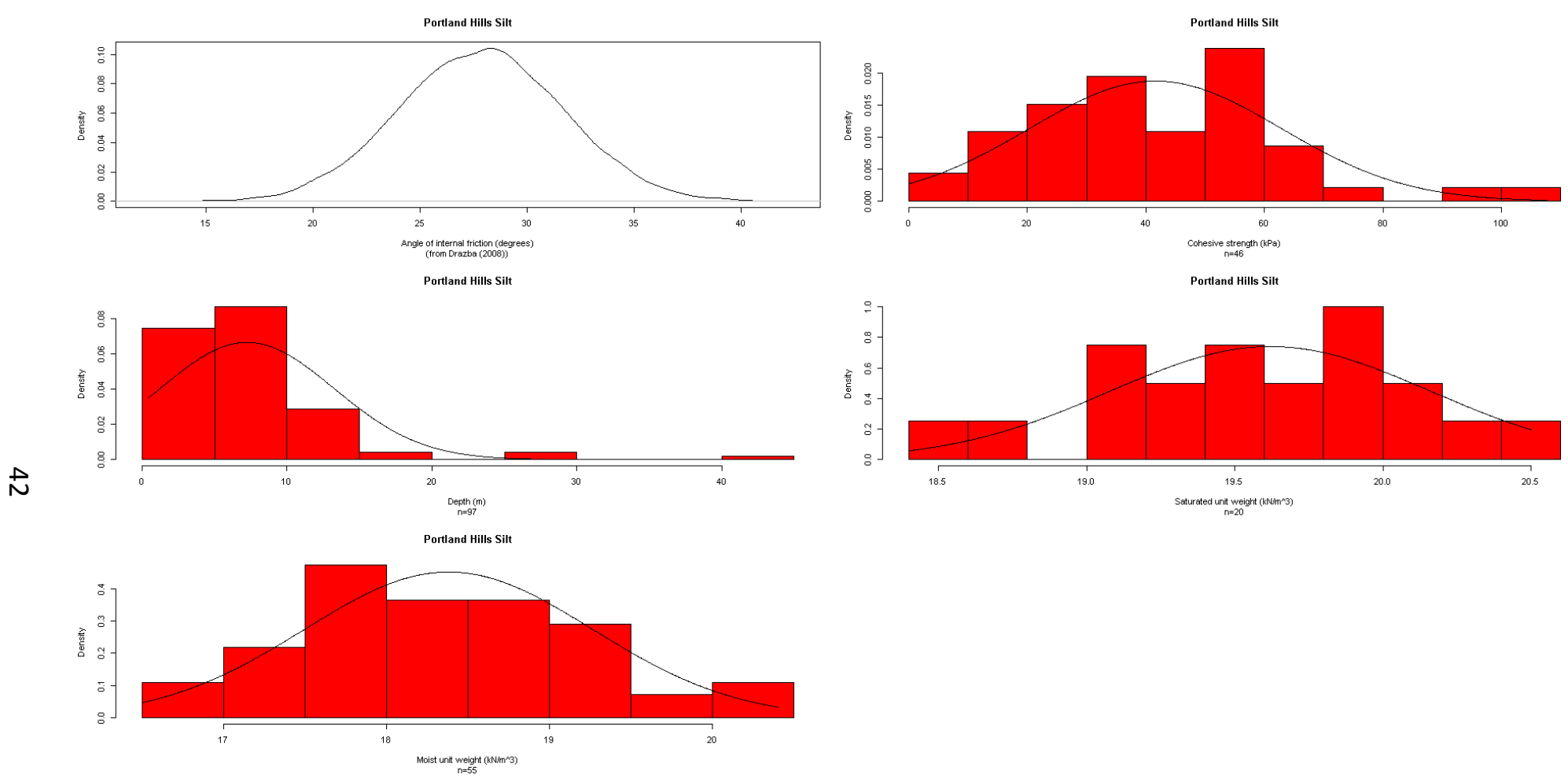

Figure 13. Histograms of PHS geotechnical data with a normal PDF for reference. Note that phi values for the PHS unit do not include a histogram as these data were derived from Drazba (2008). 

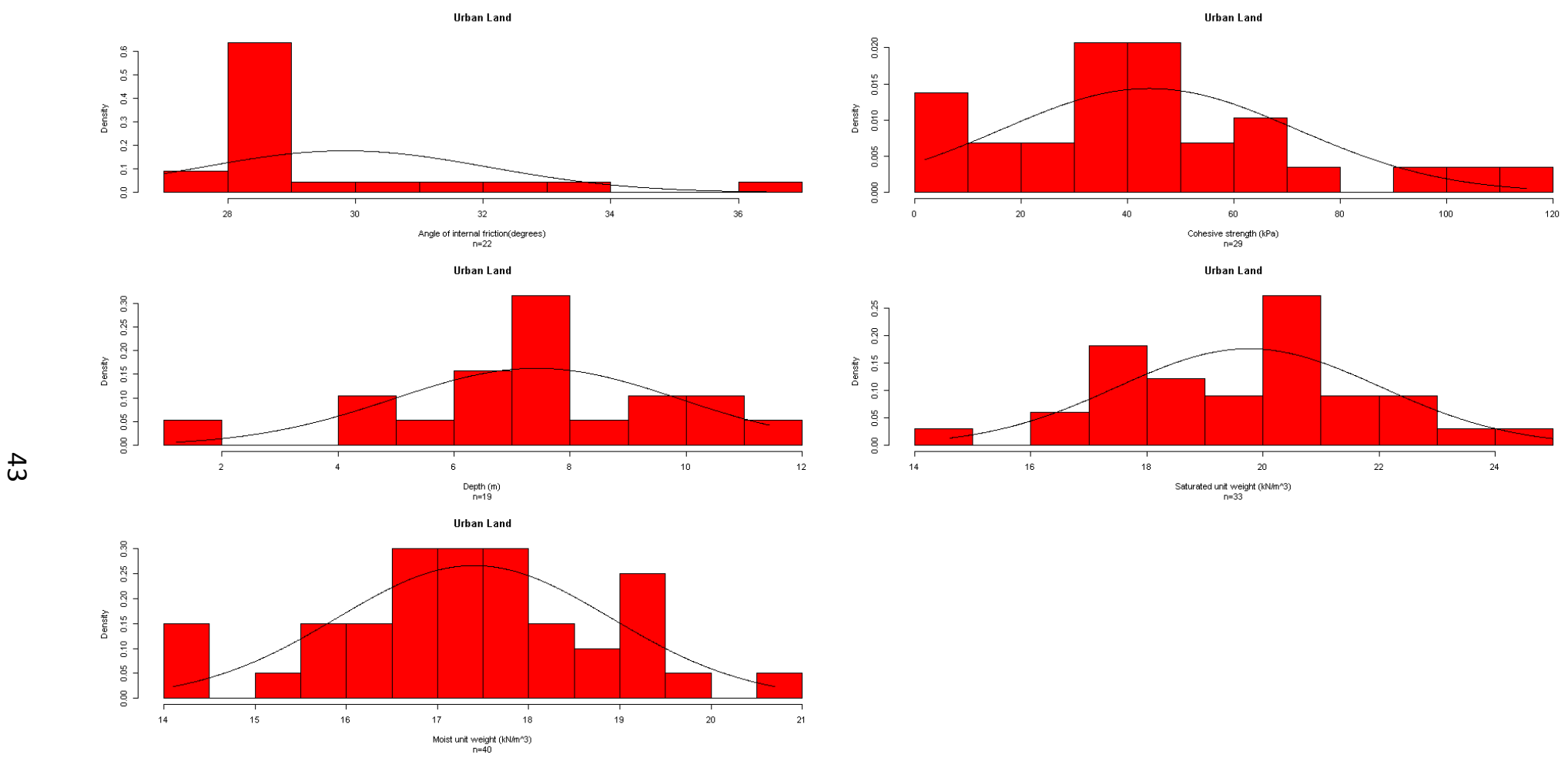

Figure 14. Histograms of URB geotechnical data with a normal PDF for reference. 

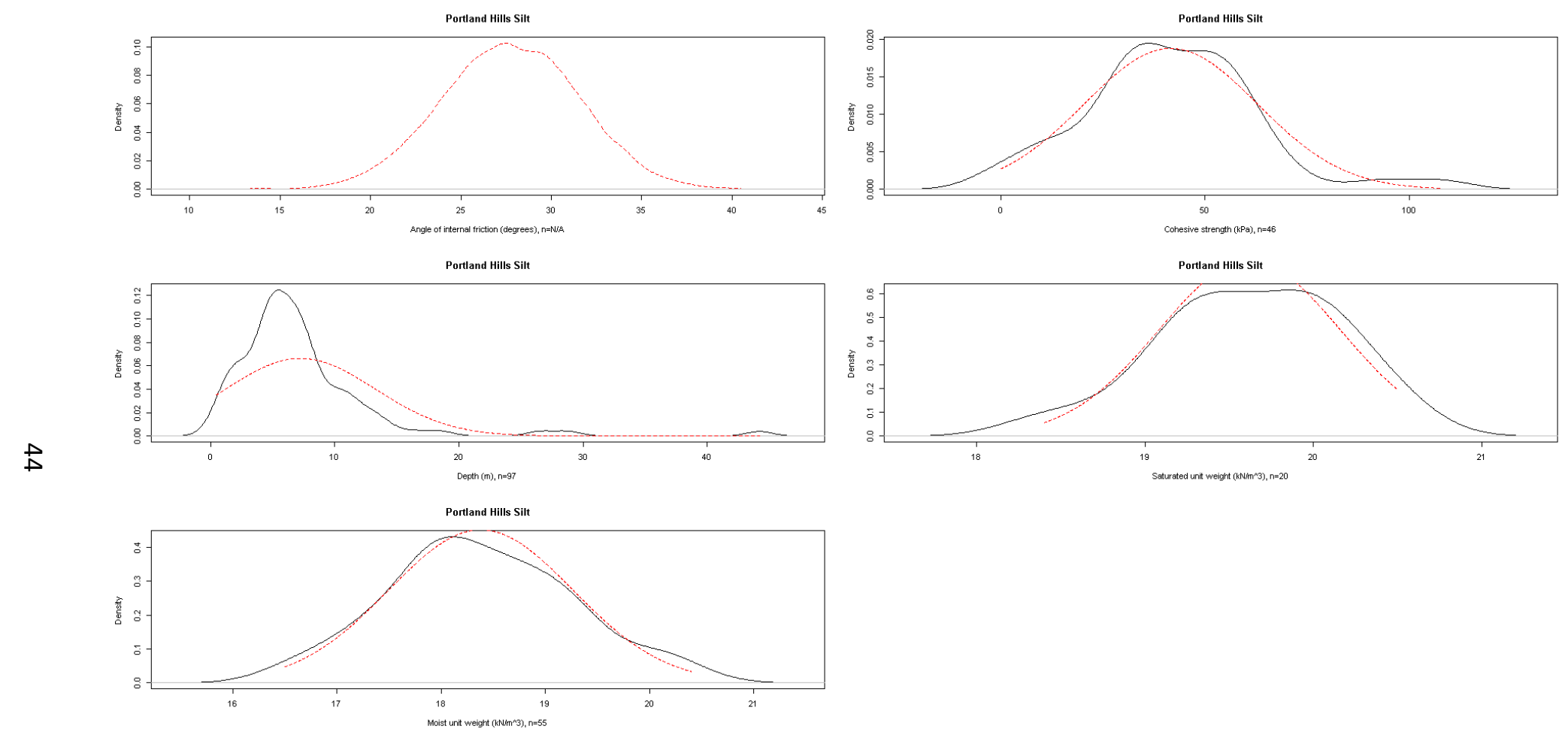

Figure 15. Density plots of PHS geotechnical data with a normal PDF (dashed line) for reference. Note that phi values for the PHS unit do not include a density plot as these data were derived from Drazba (2008). 

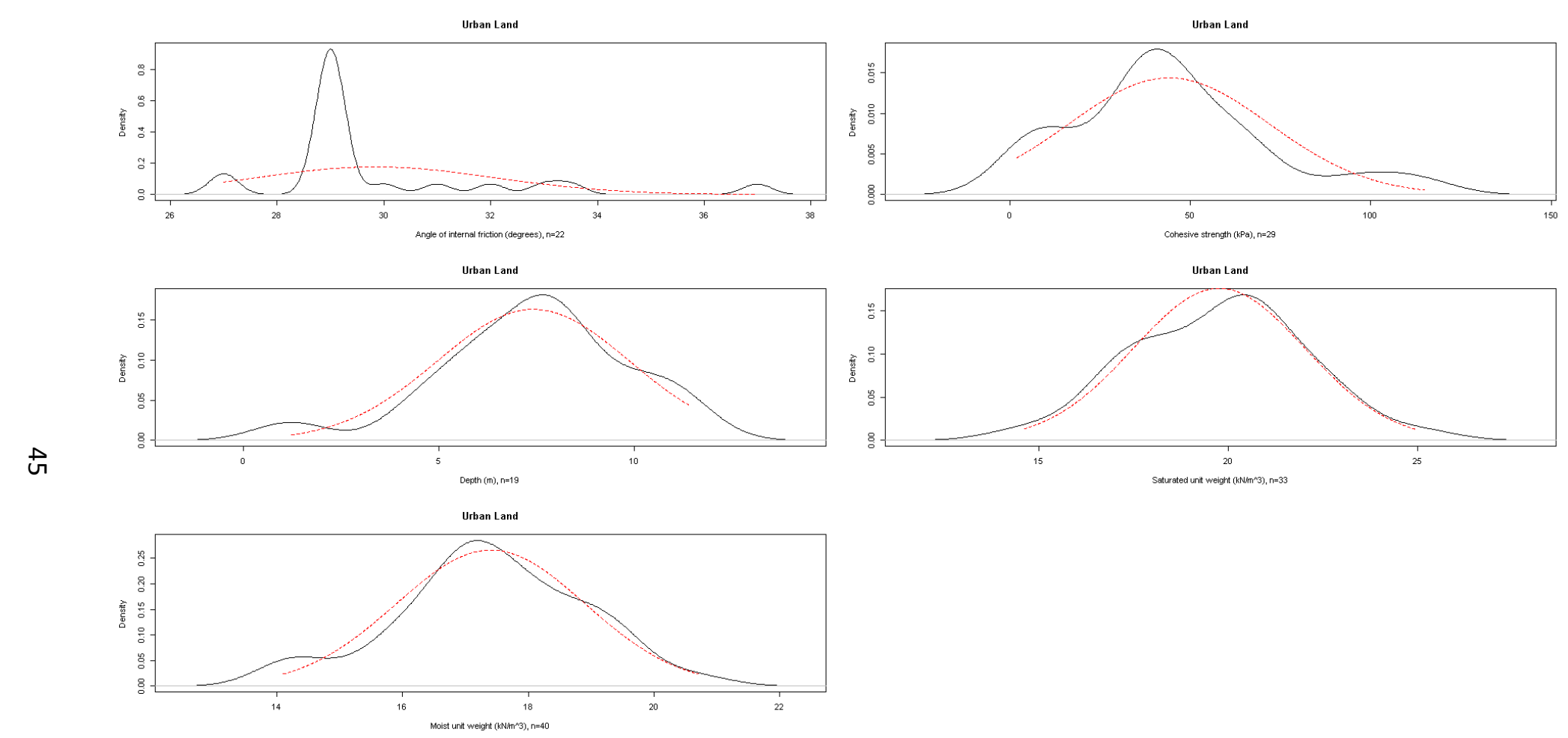

Figure 16. Density plots of URB geotechnical data with a normal PDF (dashed line) for reference. 
The density plots allow for a better visual comparison between the data and a normal PDF (e.g.: density plots of saturated unit weights for both soil types clearly suggest that the data are normally distributed, while it is not so apparent when analyzing corresponding histogram plots), and suggest, again, that some variables appear to be normally distributed, while some have some asymmetry associated with their distribution (i.e., depths of Portland Hills Silts). After comparing histograms and density plots to normal PDFs and determining which variables may be described by a normal PDF, the process involved a $\chi^{2}$ goodness-of-fit test as described by Davis (2002). The $\chi^{2}$ goodness-of-fit test follows the same process as the aforementioned $F$ and t-tests: establishing null and alternative hypotheses, calculating a test statistic, and comparing it to a table value.

In the $\chi^{2}$ goodness-of-fit test, it is hypothesized that populations from which samples are drawn are normally distributed, with the alternative being that they are not. The first step is to devise a test statistic by dividing a normal PDF into a number of equally sized classes or bins. The probability that an observation will fall within any one of the bins is equal to the area under the curve within the bin range, and from those probabilities the expected frequency of occurrence within each bin can be calculated. The observed and expected frequencies of occurrence within each bin are then calculated. If the number in each class is significantly different, it is unlikely that the sample was drawn from a normal population. A $\chi^{2}$ test statistic and table value are then 
compared to determine if the sample is significantly different from a normal population.

The test statistic is calculated by

$$
\chi^{2}=\sum_{j=1}^{k} \frac{\left(O_{j}-E_{j}\right)^{2}}{E_{j}}
$$

where $O_{j}$ is the number of observations in the $j^{\text {th }}$ class, $E_{j}$ is the number of expected observations in the $j^{\text {th }}$ class, and $k$ are the classes or bins. The shape of the $\chi^{2}$ distribution is dependent upon the degrees of freedom of the test. In this case, the number of degrees of freedom is the number of categories, $k$, minus three. One degree of freedom is lost because the distributions are constrained to a constant sum, and an additional two degrees of freedom are lost because $\mu$ and $\bar{X}$ are estimated by $\sigma^{2}$ and $s^{2}$, respectively. If the $\chi^{2}$ statistic is smaller than the $\chi^{2}$ table value, the null hypothesis fails to reject, suggesting that there is no evidence to support that the sample was not drawn from a normally distributed population. Davis (2002) suggests that as a "rule of thumb", all bins should have an expected frequency of five or greater. Scripts written in R and used in this analysis can be found in the appendix. The results of the $\chi^{2}$ tests shown in Table 9 suggest that with the exception of two variables (Portland Hills Silt depth and Urban Land angle of internal friction), there is no evidence to suggest that the remaining samples were not drawn from normal populations. 
Table 9. Result of various $\chi^{2}$ tests comparing soils variables against a normal PDF.

\begin{tabular}{lccccc}
\hline Variable & $\boldsymbol{\alpha}$ & DOF & $\boldsymbol{\chi}^{2}$ stat & $\boldsymbol{\chi}^{2}$ table & Result \\
\hline \hline Phi & \multicolumn{5}{c}{ Portland Hills Silt } \\
Cohesive strength & NA & NA & NA & NA & NA \\
Depth & 0.05 & 6 & 12.3 & 12.6 & $\mathrm{~F}$ \\
Moist unit weight & 0.05 & 7 & 42.8 & 14.1 & $\mathrm{R}$ \\
Saturated unit weight & 0.05 & 7 & 4.8 & 14.1 & $\mathrm{~F}$ \\
& 0.05 & 1 & 1.6 & 3.8 & $\mathrm{~F}$ \\
\hline Phi & & Urban Land & & & \\
Cohesive strength & 0.05 & 1 & 18 & 3.84 & $\mathrm{R}$ \\
Depth & 0.05 & 2 & 2.6 & 6 & $\mathrm{~F}$ \\
Moist unit weight & 0.05 & 1 & 1 & 3.8 & $\mathrm{~F}$ \\
Saturated unit weight & 0.05 & 5 & 2.8 & 11.1 & $\mathrm{~F}$ \\
\hline & 0.05 & 3 & 1 & 7.8 & $\mathrm{~F}$ \\
\hline
\end{tabular}

Inspection of Figure 15 and Figure 16 reveal that 1) the depth variable of the PHS soil unit has some skewness and kurtosis associated with its density plot, and that 2) the phi variable of the URB soil unit is not normally distributed and appears to be highly kurtotic about a central value. Given these observations, it is hypothesized and assumed that an extreme value type-I or Gumbel distribution may better describe the distribution of the aforementioned variables. Using the "evd" package in R (Stephenson, 2012), location and scale parameters for Gumbel distributions were determined for the variables discussed above and were plotted for each soil unit as shown in Figure 17 and Figure 18. Table 10 lists the final probability distributions that were used as input into PISA-m. 

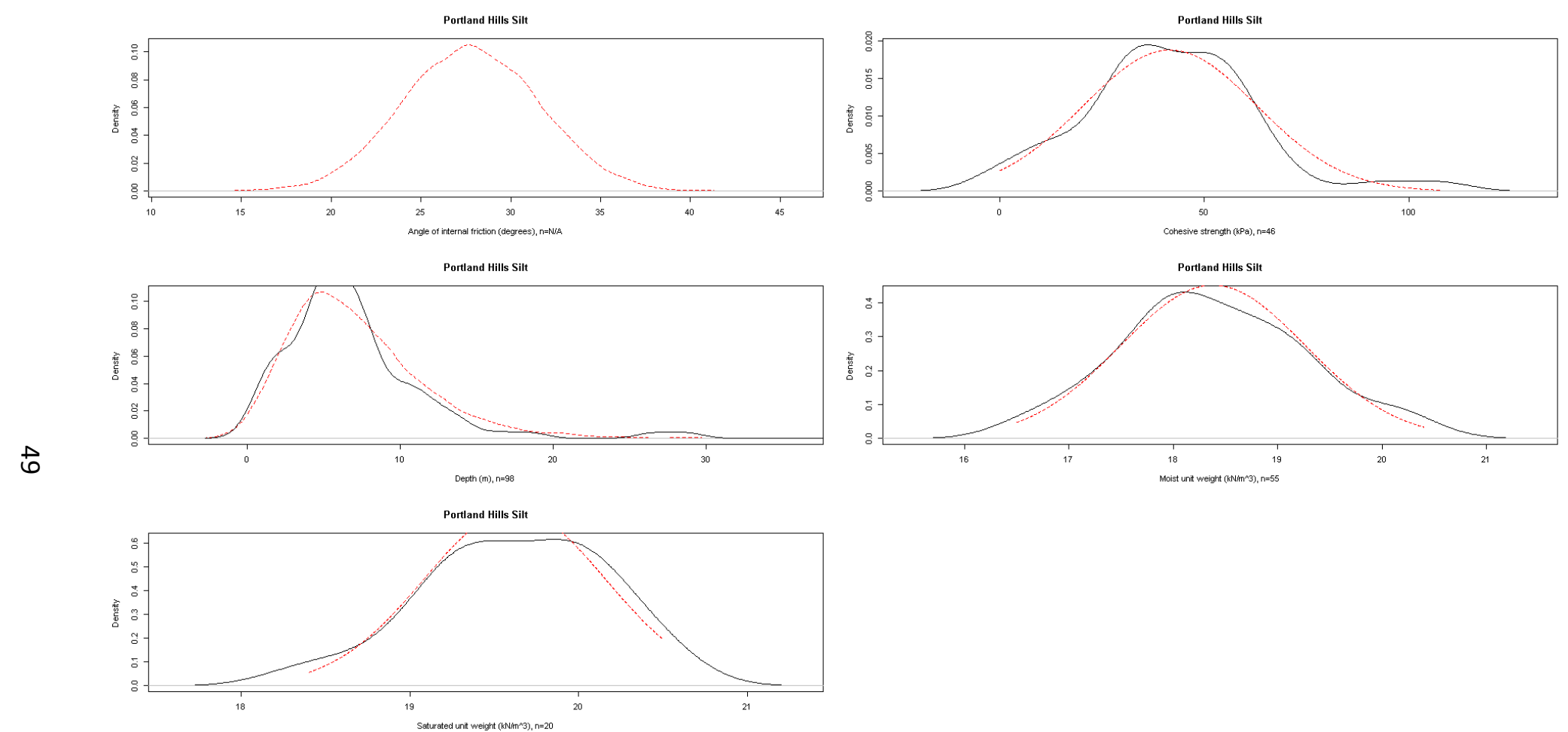

Figure 17. Final probability distributions for the PHS soil unit used as input into PISA-m. Solid lines are density plots of the data while the dashed lines are PDFs fitted to the data. 

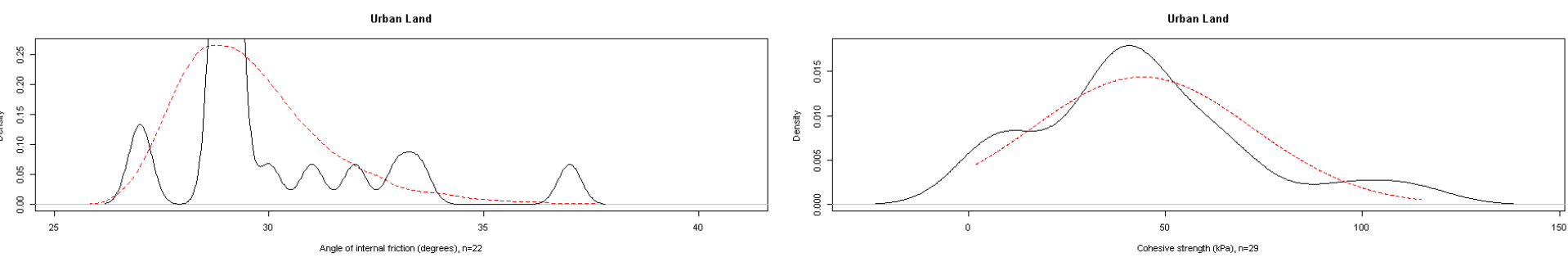

Urban Land
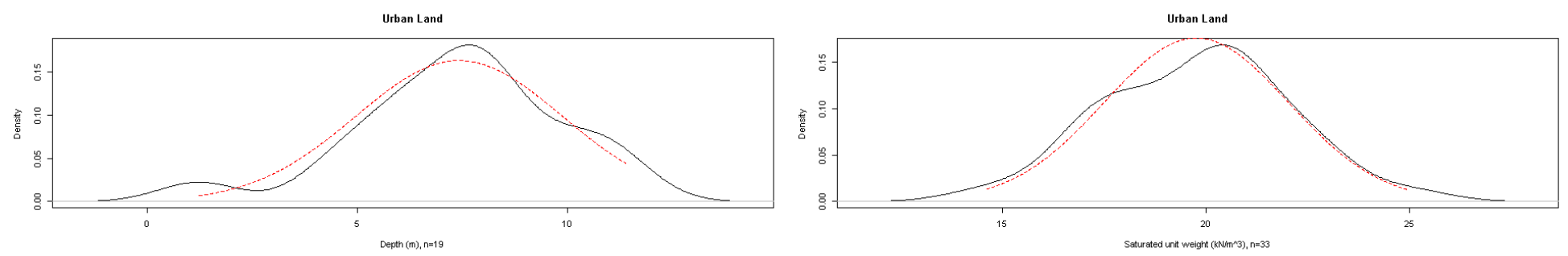

Urban Land

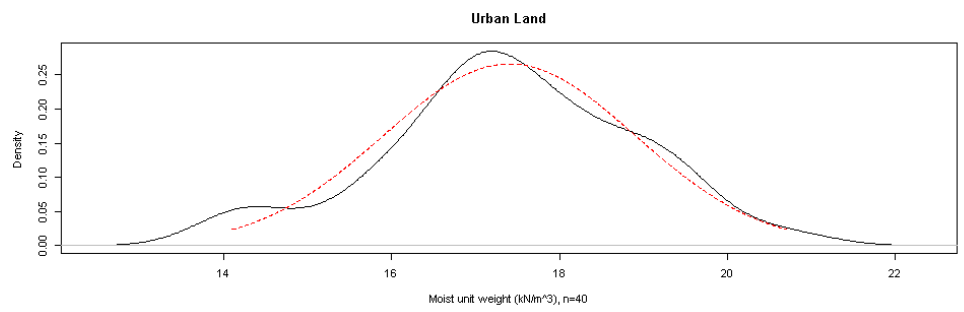

Figure 18. Final probability distributions for the URB soil unit used as input into PISA-m. Solid lines are density plots of the data while the dashed lines are PDFs fitted to the data. 
Table 10. Final distributions and parameters used in soil parameter file.

\begin{tabular}{|c|c|c|c|c|c|}
\hline Variable & Distribution & Mean & $\begin{array}{l}\text { Standard } \\
\text { Deviation } \\
\end{array}$ & $\begin{array}{c}\text { Location } \\
\text { Parameter }(\alpha) \\
\end{array}$ & $\begin{array}{c}\text { Scale } \\
\text { Parameter ( } \beta \text { ) } \\
\end{array}$ \\
\hline \multicolumn{6}{|c|}{ Portland Hills Silt (PHS) } \\
\hline $\operatorname{Phi}\left(\left(^{\circ}\right)\right.$ & Normal & 27.8 & 3.8 & - & - \\
\hline $\begin{array}{l}\text { Choesive strength } \\
\text { (kPa) }\end{array}$ & Normal & 41.6 & 21.2 & - & - \\
\hline Depth (m) & Gumbel & - & - & 5.1 & 3.4 \\
\hline $\begin{array}{l}\text { Moist unit weight } \\
\left(\mathrm{kN} / \mathrm{m}^{\wedge} 3\right) \\
\text { Saturated unit } \\
\text { weight }\left(\mathrm{kN} / \mathrm{m}^{\wedge} 3\right)\end{array}$ & $\begin{array}{l}\text { Normal } \\
\text { Normal }\end{array}$ & $\begin{array}{l}18.4 \\
19.6 \\
\end{array}$ & $\begin{array}{l}0.9 \\
0.5 \\
\end{array}$ & - & - \\
\hline \multicolumn{6}{|c|}{ Urban Land (URB) } \\
\hline Phi $\left({ }^{\circ}\right)$ & Gumbel & - & - & 28.9 & 1.4 \\
\hline $\begin{array}{l}\text { Cohesive strength } \\
(\mathrm{kPa})\end{array}$ & Normal & 44.1 & 27.8 & - & - \\
\hline Depth (m) & Normal & 7.4 & 2.5 & - & - \\
\hline $\begin{array}{l}\text { Moist unit weight } \\
\left(\mathrm{kN} / \mathrm{m}^{\wedge} 3\right) \\
\text { Saturated unit } \\
\text { weight }\left(\mathrm{kN} / \mathrm{m}^{\wedge} 3\right)\end{array}$ & $\begin{array}{l}\text { Normal } \\
\text { Normal }\end{array}$ & $\begin{array}{l}17.4 \\
19.8\end{array}$ & 1.5 & - & - \\
\hline
\end{tabular}

Once relevant soil types within the watershed were established and appropriate PDFs were assigned to their engineering characteristics, the final step in creation of the soils raster for input into PISA-m was to create the soil map file using ESRI's Arc-GIS 10.1. This required reclassifying and combining the three Cascade-Urban Land complexes, Goble silt loam and Haploxeroll soils into the aforementioned PHS soil unit. The same process was performed with the Urban Land and Sauvie soils, creating the aforementioned URB soil unit. In an effort to completely characterize the watershed, it was assumed that the Delena and Quafeno soils had similar engineering characteristics to the URB soil unit and were subsequently spatially incorporated into the URB soil unit. This incorporation is assumed to have a minimally significant effect on stability 
calculations as the two soil types had an insignificant percentage within the watershed, and the Quafeno soil is considered to be the dominant soil within the larger Urban Land Complex according to Green (1983). After creating the combined PHS and URB soil units, the spatial data were converted from shapefile to ASCII grid format in ArcGIS. This required a vector to raster conversion and required that the output cell size parameters of the soil map match the raster resolution of the LiDAR data for PISA-m to function properly.

\section{Vegetation raster}

Trees on the surface of a slope have the potential to increase or decrease the factor of safety against slope failure through tree root cohesion and tree surcharge, respectively. The relationship between trees and slope stability is well documented (Hammond et al., 1992) and depends on a multitude of factors including soil type, rainfall regime, tree species, slope aspect, and many tree root characteristics including root tensile strength, depth, orientation, health, and density (Schmidt et al., 2001). Tree roots are thought to provide additional shear strength to a soil mass in three ways (Hammond et al., 1992) by: 1) providing a laterally reinforcing surface layer that acts as a membrane to hold the underlying soil in place, 2) anchoring an unstable soil mantle to stable subsoils or bedrock where the roots penetrate a potential failure surface, and 3) acting as buttress piles or arch abutments, or both, to support the soil uphill from the trees. Burroughs and Thomas (1977) determined root cohesion values for Douglas-fir forests in Oregon (the same type of forest found in the Stephens Creek Watershed) by 
measuring root diameters and strength, applying direct shear tests in forest soils, and using back-calculation, and determined that the cohesive strength varied from 7.5-17.5 kPa (157-365 psf). These values were assumed to be normally distributed and representative of the Stephens Creek Watershed and were used in this analysis.

The weight of trees on a slope also has the potential to add an additional load, increasing the driving forces acting on the slope through tree surcharge. Tree surcharge depends on the size, species, and density of the trees (Hammond et al., 1992). Without these data, Hammond suggests that estimates of tree surcharge can be taken from the literature. It is important to note, however, that tree surcharge values have a relatively insignificant effect on the factor of safety of a slope.

Haneberg (2000) describes a method of describing the sensitivity of the factor of safety to the independent variables used in the infinite slope equation. The normalized percent change in the $i^{\text {th }}$ independent variable, $x_{i}$, in a model is given by

$$
\Delta x_{i}=\frac{x_{i}-\bar{x}}{x_{\max }-x_{\min }} \times 200 \%
$$

and the normalized percent change in the factor of safety is given by

$$
\Delta F S=\left(\frac{F S\left(x_{i}\right)-F S(\bar{x})}{F S(\bar{x})}\right) \times 100 \%
$$

where $\bar{x}$ is the average value, $x_{\min }$ is the minimum value, and $x_{\max }$ is the max value of the $i^{\text {th }}$ independent variable. The sensitivity of the factor of safety to the variation of each 
independent variable is determined by varying $x_{i}$ continuously from $x_{\min }$ to $x_{\max }$, calculating $\Delta F S$ and $\Delta x_{i}$ for each value of $x_{i}$, and then plotting $\Delta F S$ versus $\Delta x_{i}$. Figure 19 shows the result of a sensitivity analysis performed using values derived from the City of Portland's Public Works Database in this study. Figure 19 was generated using average values for each independent variable and allowing them to vary over the range of standard deviations shown in Table 8. The height of the phreatic surface was assumed to have an average value of 0.5 and was allowed to vary between 0 and 1 (fully dry to fully saturated conditions). The results indicate that although the factor of safety is slightly sensitive to root cohesive strength and tree surcharge, it is most sensitive to depth and cohesive strength of the soil, slope angle, and height of the phreatic surface. Given the small sensitivity of the factor of safety to tree surcharge, and the unavailability of data required to calculate it, it is assumed in this study that there is no effect from tree surcharge in the Stephens Creek Watershed.

The vegetation raster used in this study was developed using "highest hit" or "first return" LiDAR data coupled with high resolution orthoimagery obtained from the USGS (GPS Surveying Inc., 2002). The process involved scanning the highest hit LiDAR data for forested areas and using air photos to verify tree canopy extent (Figure 19). After delineating the forest cover and creating the vegetation layer, the shapefile was converted from vector to raster to create the vegetation raster shown in Figure 21. 


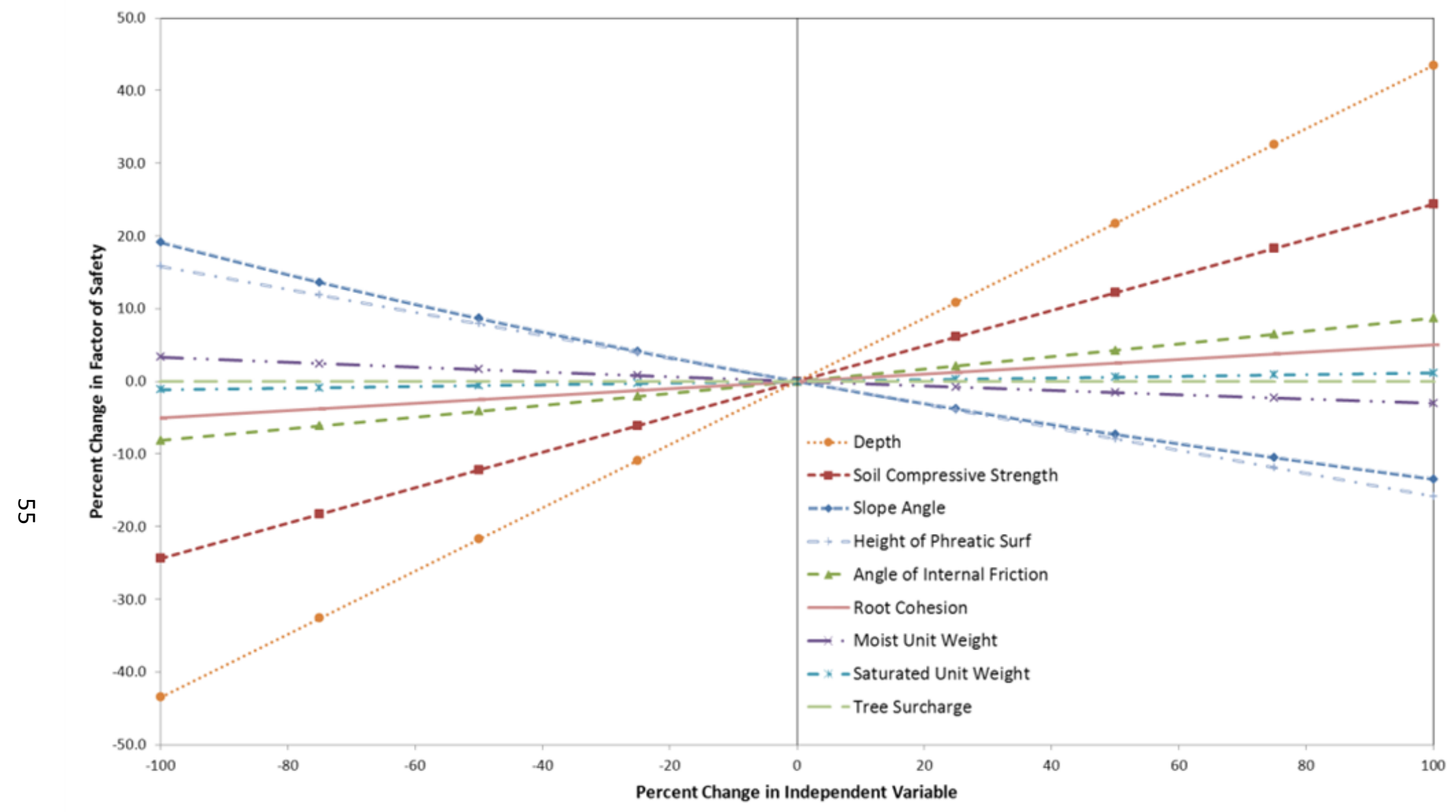

Figure 19. Sensitivity analysis of variables used in the infinite slope equation (Eq. 1), using values determined in this study. 

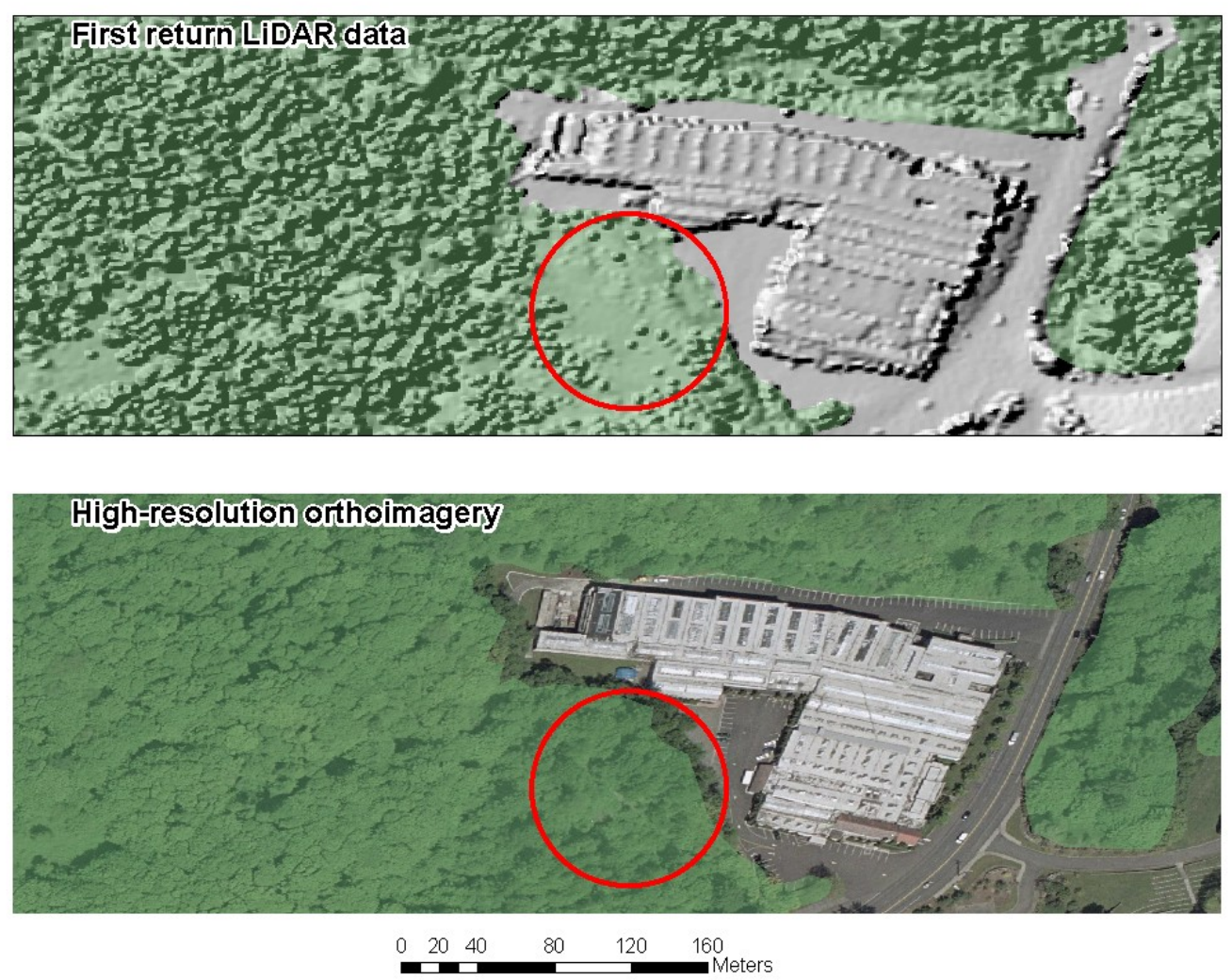

Figure 20. Comparison of highest hit LiDAR data and high resolution air photos used to delineate forest cover. The red circle in the images shows how air photos were used to verify canopy cover from the LiDAR. In this case, the LiDAR data suggest there are no trees within the red circle. Comparison with the high resolution orthoimagery, however, indicates that trees are indeed present and were subsequently mapped as such. 


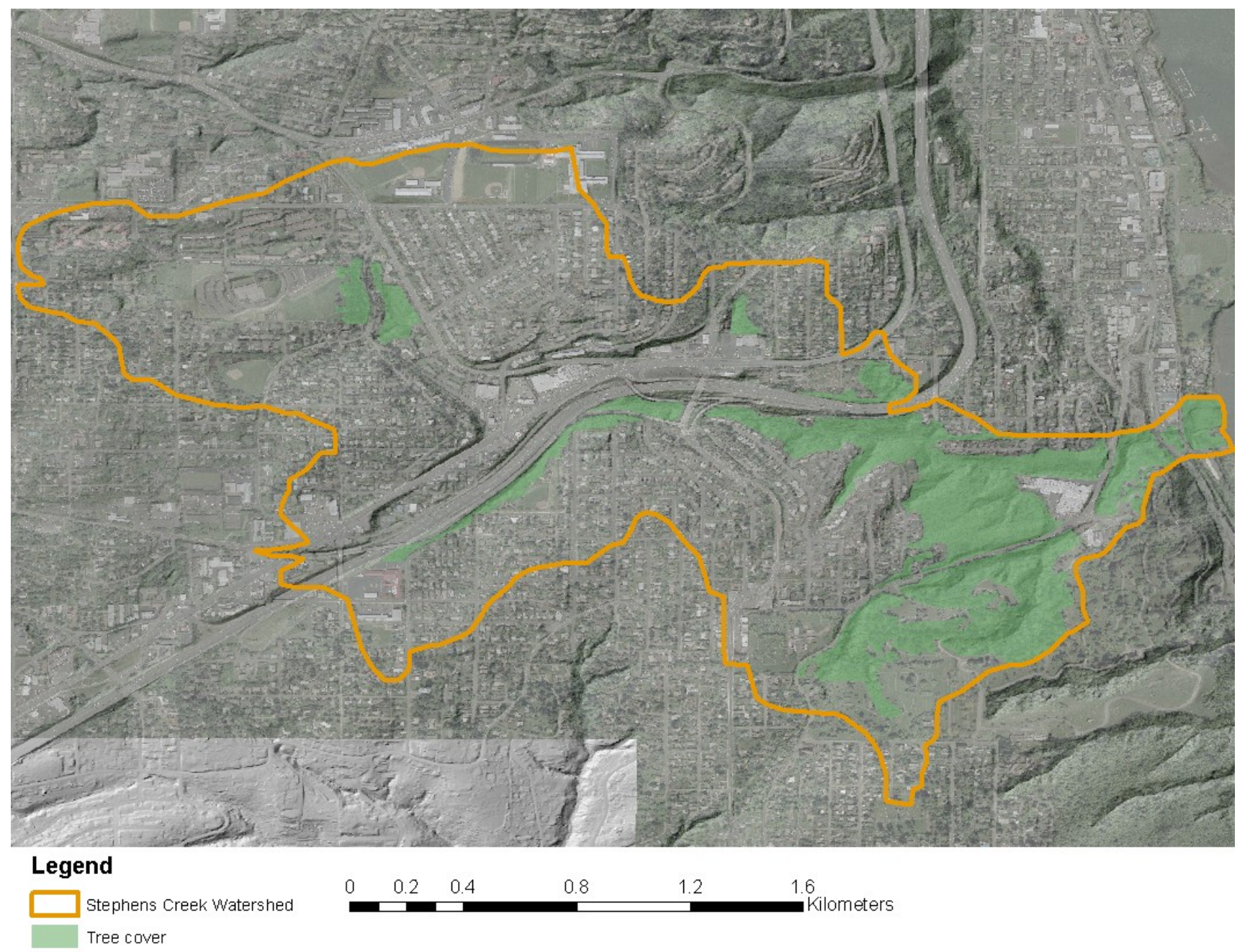

Figure 21. Map showing the final extent of the vegetation raster used in the analysis. 


\section{Parameter file}

Once the three raster map files were created in ArcGIS, they were converted to .ASCII files for use in PISA-m. The next and final step in preparing data for PISA-m to perform slope stability calculations was creating the parameter file that correlates engineering data to the map files. Data extracted from the database include depth to bedrock, saturated and moist unit weights, soil cohesive strength, and angle of internal friction, when available. These data and their associated PDFs were used as input in the parameter file, an example of which can be found in the appendix. Other data incorporated in the parameter files include constants such as the elevation error associated with LiDAR data and the minimum slope angle used in slope stability calculations. Since groundwater data were generally not available within the Stephens Creek Watershed, data regarding the height of the phreatic surface were modeled as best (fully dry) and worst (fully saturated) case conditions. In order to model these conditions, phreatic surfaces were input with values of 0 and 1 for dry and saturated conditions, respectively, with uniform PDFs.

\section{PISA-m Output File}

The output from PISA-m consists of an ASCII file that calculates a probability that the FOS is $\leq 1\left(P_{F O S \leq 1}\right)$ for each LiDAR grid cell. In order to produce a probability map that is relatively easy to visually and numerically interpret, a symbology scheme was developed for the output data. For this analysis, the output data were classified manually in $4 \mathrm{P}_{\mathrm{FOS} \leq 1}$ bin classes (bin 1: $0.0-0.25$, bin 2: $0.25-0.50$, bin $3: 0.50-0.75$, 
and bin 4: $0.75+$ ) based on a similar analysis by Haneberg (Haneberg, 2009). Since only fully dry and fully saturated conditions were modeled, any cells that fell within bin 1

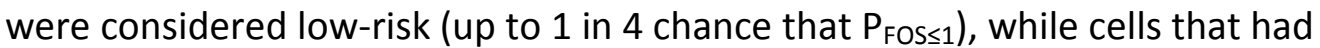
probabilities greater than 0.25 were considered high-risk (greater than 1 in 4 chance that $\left.P_{F O S \leq 1}\right)$. These categories are shown in Figure 22. 


\section{Chapter 4: Results}

The results of running PISA-m for both dry and saturated static conditions are shown in Figure 22. The data suggest that total area within the watershed that has $P_{\text {Fos } \leq 1}$ $>0.25$ is $3.7 \%$ and $23.7 \%$ for dry and saturated conditions, respectively. This indicates that the watershed transitions from being relatively stable $(96.3 \%$ of total watershed area having $\left.P_{F O S \leq 1}<0.25\right)$ during dry soil conditions, to being somewhat unstable $(76.4 \%$ of total watershed area having $P_{\mathrm{FOS} \leq 1}>0.25$ ) during saturated soil conditions. Transitioning from dry to saturated conditions increases the combined area that has $P_{\text {Fos } \leq 1}>0.25$ by $19.9 \%$ (Figure 22 ).

Figure 23 and Figure 24 show the dry-static and saturated-static probability maps, respectively. It appears that high risk areas occur mainly on steep slopes adjacent to Stephens Creek and its tributaries, as well as cut/fill slopes adjacent to the I-5 corridor, Barbur Boulevard, and SW Taylor's Ferry Road. This is to be expected, as the third most effective variable regarding sensitivity of the FOS from the infinite slope equation is slope angle. Some minor potentially unstable areas exist within surrounding housing developments located on relatively flat ground, but again, appear to correlate spatially with cut/fill slopes or naturally occurring steep topography. Comparison of the two probability maps suggests that the locations of potentially unstable slope areas have nearly the same spatial extent, but vary in terms of the degree of instability. For example, the majority of the Stephens Creek Canyon (downstream of the I-5 corridor) and its tributaries transition from mostly stable $\left(P_{\mathrm{FOS} \leq 1}<0.25\right)$ to mostly unstable $\left(P_{\text {FOS } \leq 1}\right.$ 
$>0.25$ ) for dry and saturated conditions, respectively (Figure 24). Figure 25 compares the saturated-static probabilities map to historic landslides from Burns et al. (1998) and Burns and Duplantis (2010) and seems to validate model results. Additionally, landslides resulting from the 100-year return interval storm event of February 1996 (Burns, 1996) spatially correlate very closely to high-risk areas from both dry and saturated static conditions, although slide event locations do not consistently fall within high risk value $\left(P_{\text {FOS } \leq 1}>0.25\right)$ cells. This may be attributed to positional error in GPS field units, field observer position relative to actual landslide centroid at the time of positional data capture, or model errors.

Given the results shown in the previous figures, an "avoidance" area map was developed as shown in Figure 26. The avoidance map was delineated to contain any historic as well as ancient landslides, as well as high risk areas where $P_{\text {Fos } \leq 1}>0.25$ for saturated static conditions. The avoidance area accounts for $38.1 \%$ of the total area within the Stephens Creek Watershed. It is important to note that the avoidance areas are not simply places where infiltration should not be located, but locations where an increase in pore water would likely increase $\mathrm{PFOS} \leq 1$, and are considered to be high risk for infiltration. This means that downslope or lateral movement of groundwater from infiltration locations outside of the avoidance areas could potentially enter avoidance areas and the placement of infiltration systems should consider this before construction is initiated. 


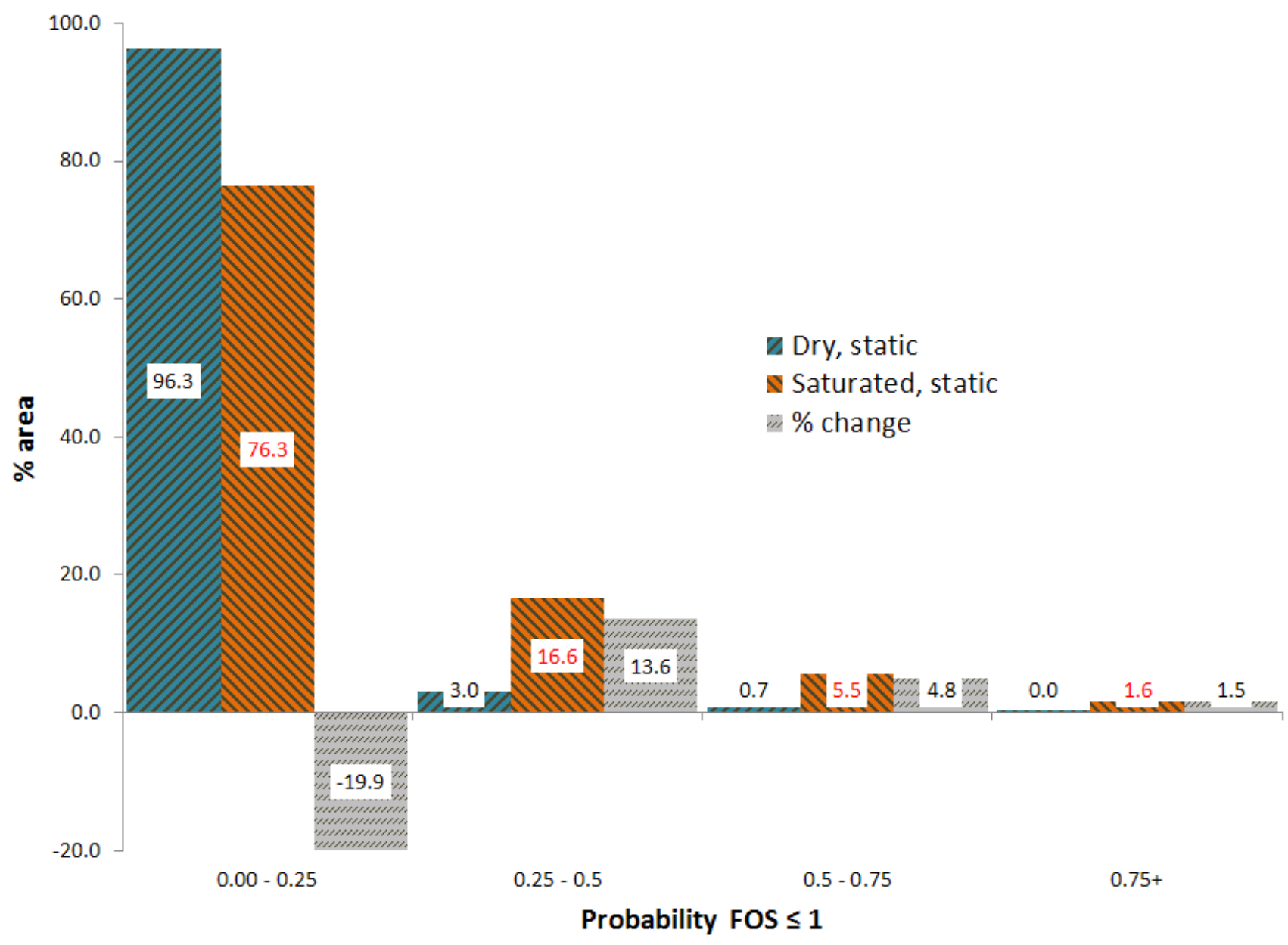

Figure 22. Histogram showing the percent area of the watershed that is defined by FOS probability bins. 


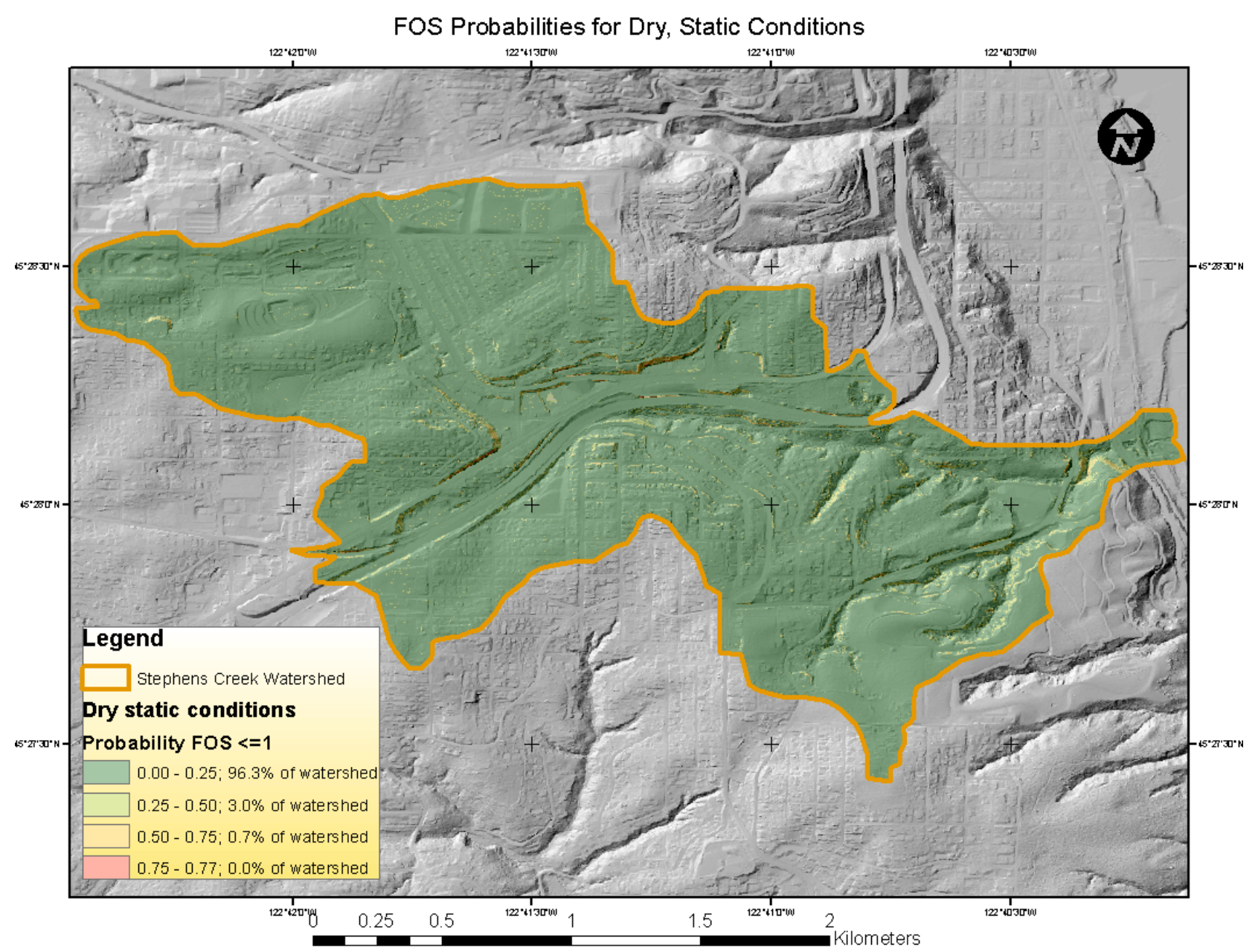

Figure 23. Map of probabilities that the FOS $\leq 1$ for dry, static conditions within the Stephens Creek Watershed. 


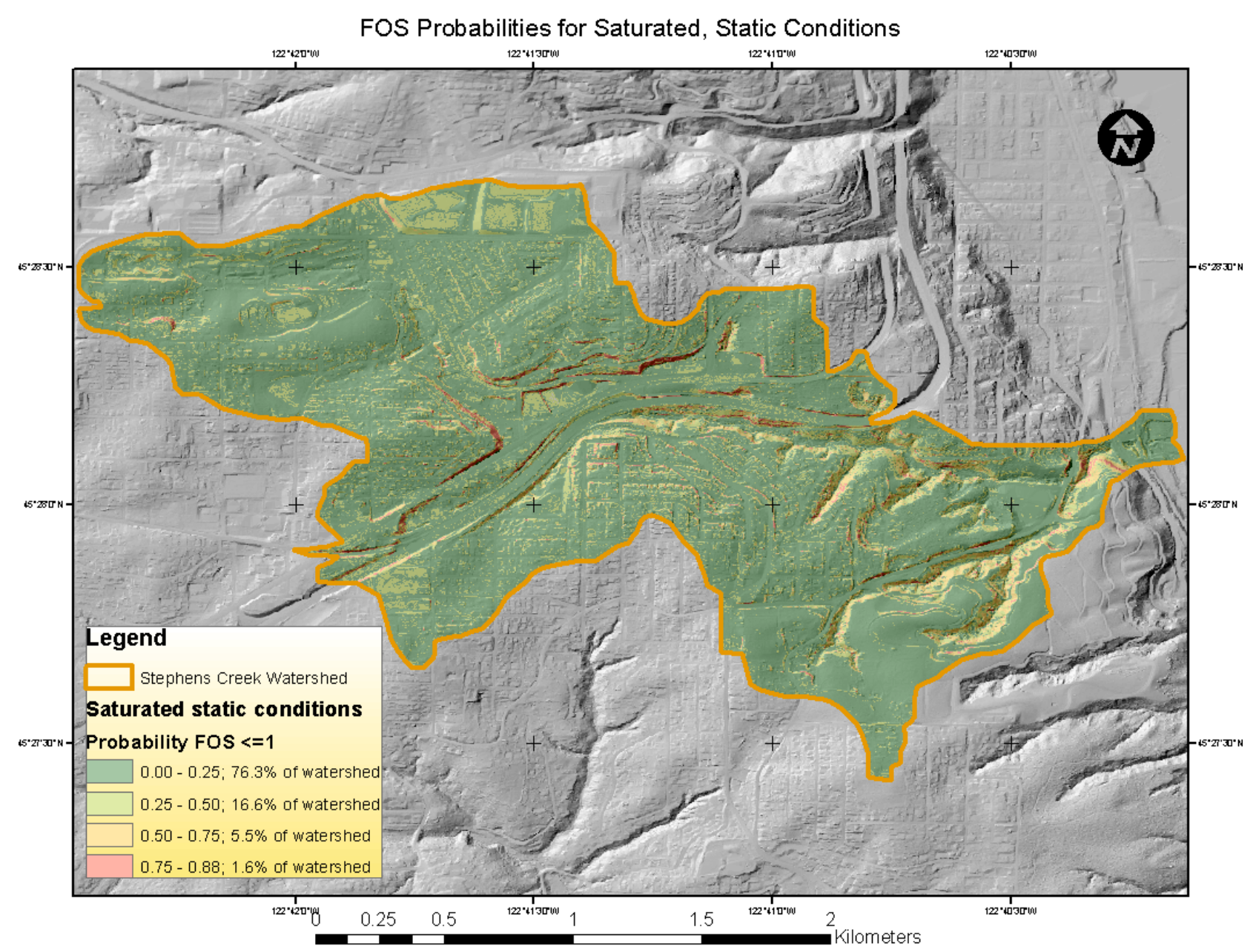

Figure 24. Map of probabilities that the FOS $\leq 1$ for saturated, static conditions within the Stephens Creek Watershed. 


\section{Probability Map/Landslide Inventory Comparison}

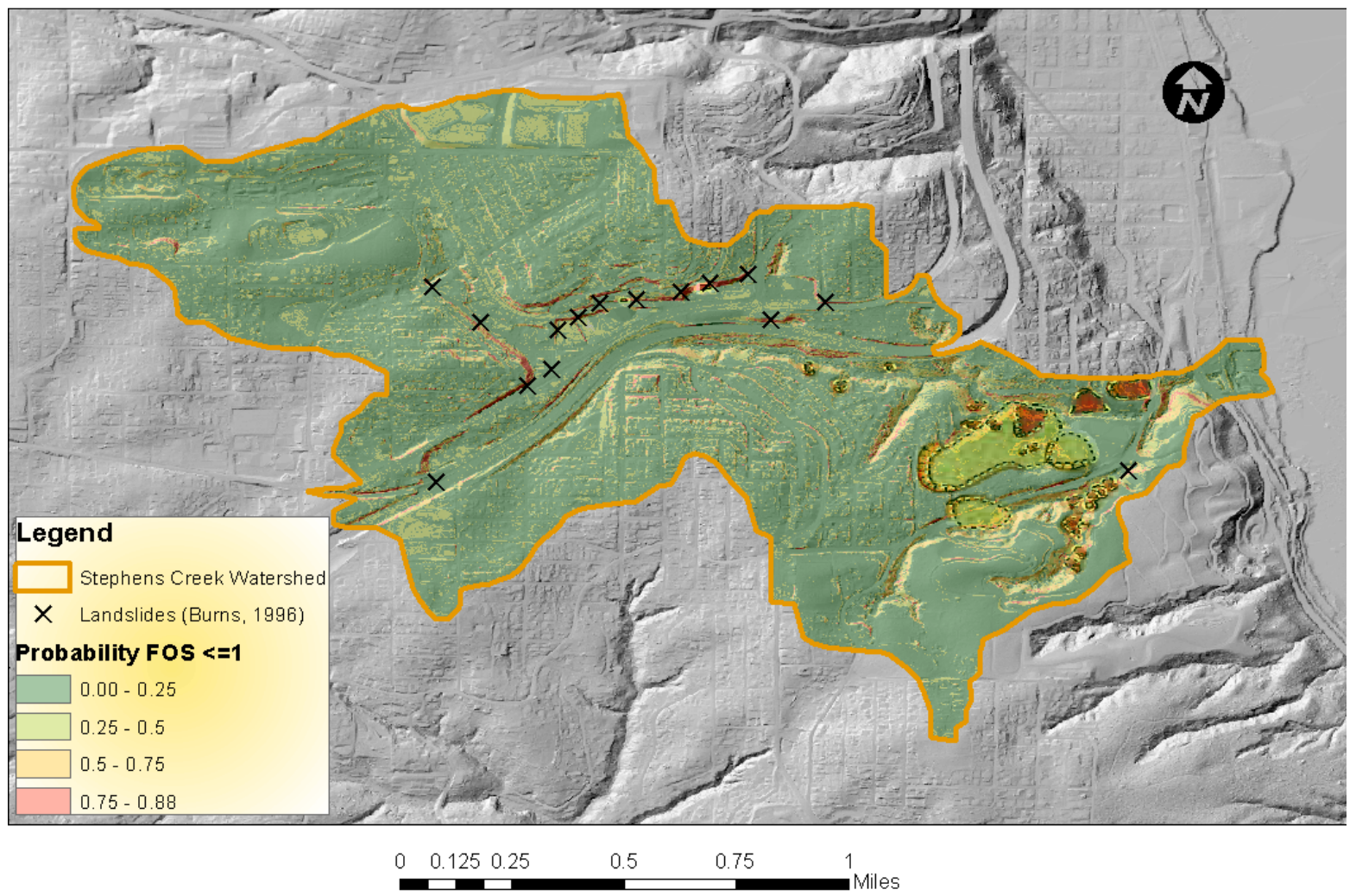

Figure 25. Maps showing probabilities compared to historic and ancient landslides indicating good correlation between modeled probabilities and slope failures. Historic landslide points from February 1996 storm (Burns, 1996), and ancient landslide polygons (modified from Burns and Duplantis, 2010). 


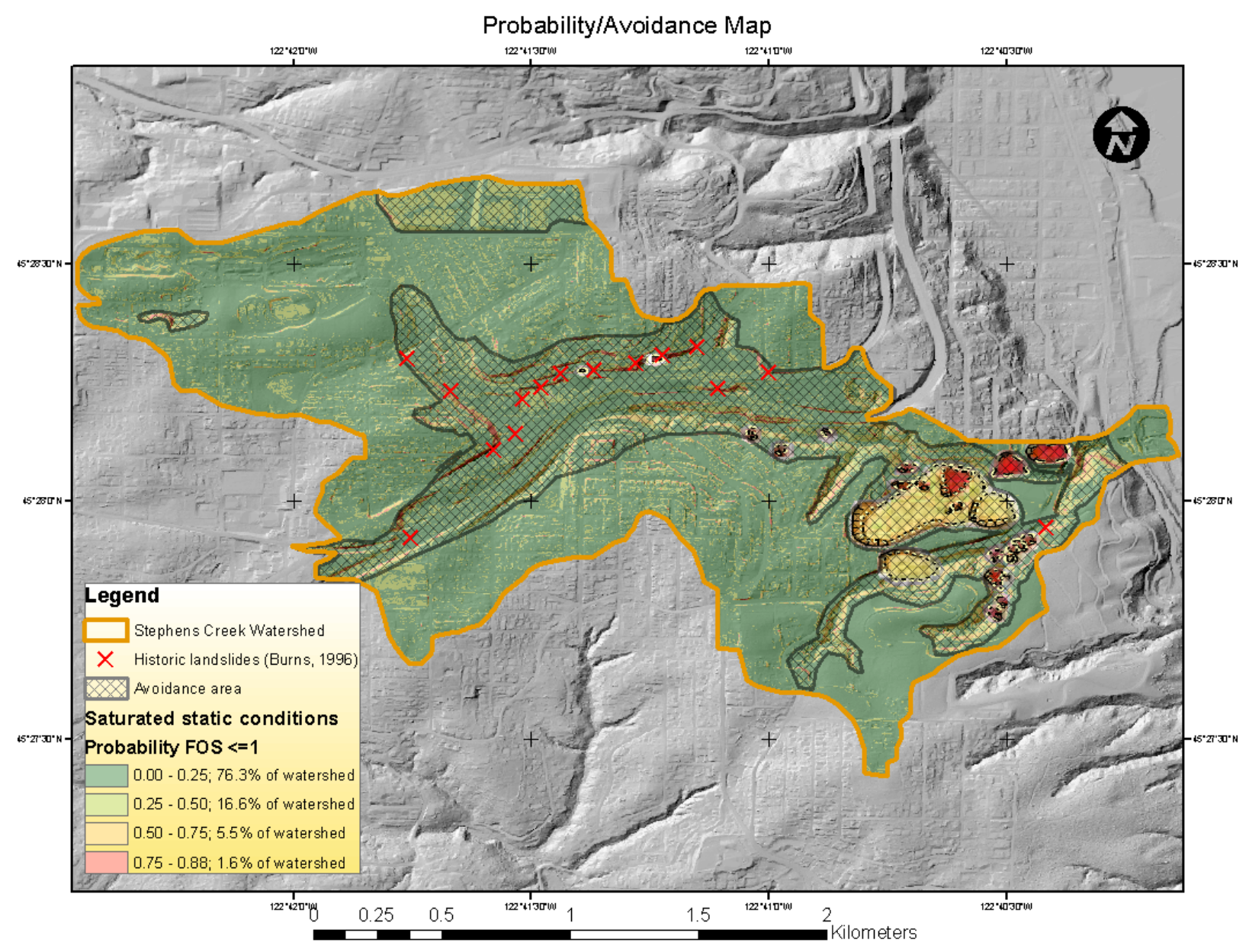

Figure 26. Avoidance map, showing areas that should avoid having any water infiltrated into them. The avoidance areas contain sites of historic/ancient landslides, as well as high risk probability areas. 


\section{Chapter 5: Discussion}

Slope stability modeling results in this study support the observation that the Stephens Creek Watershed is highly prone to slope failure. This is not surprising as natural and man-made slope conditions promote unstable slopes and are predictable based on their locations. Comparison of model results to that of historic landslide data suggests a validation of model results. Although there is generally good agreement between model results and historic landslide data, there are also model uncertainties and weaknesses that should be considered. Statistician George Box (Box and Draper, 1987) was famously quoted as saying, "essentially, all models are wrong, but some are useful", and the modeling effort conducted here is no exception.

Model uncertainties and weaknesses in this study arise from a multitude of factors. One such factor is that data used to create soil engineering property distributions are potentially inaccurate. In this study, reports from the BES Public Works Database were examined to extract engineering data for use in the soils raster. Data extracted from these reports often relied on the author's interpretation of a given report. For example, the depth of soil within a borehole may only have been indicated by a change in the rate of drilling or a driller's interpretation of cuttings lithology. Incorrect interpretation of these data in this example would lead to inaccurate model probability distributions and ultimately result in model bias, although the depth to bedrock is relatively easy to interpret (Scott Burns, personal communication 2011). Additionally, even if data used in this study were accurate regarding measured 
properties, the sample statistics may not be completely representative of soil population parameters.

Other sources of model biases are the many assumptions made in this study.

Given the sensitivity analysis presented in Figure 19, it was assumed that tree surcharge pressure had a negligible effect on the FOS and could be modeled with no pressure effect. Although the analysis showed that tree surcharge had a negligible effect on the FOS, site specific conditions within the watershed could potentially be more affected by tree surcharge. Another assumption was made regarding probability distributions used in this study. For example, that assumption that data that did not conform to normal PDFs (based on $\chi^{2}$ tests) could be represented with extreme value PDFs was based solely on visual comparison of density plots to extreme value PDFs that were fit to the collected data. This is in stark contrast to statistically testing the data for conformance to various PDFs and subsequently choosing the most appropriate PDF.

Lastly, modeled best and worst case scenarios, represented by fully dry and saturated conditions, respectively, do not necessarily reflect actual anticipated field conditions. Phreatic surface scenarios used in this study were not allowed to vary, and instead were modeled by uniform PDFs. This means that the resulting probability maps are only representative of the aforementioned best and worst case scenarios and may overestimate $\mathrm{P}_{\mathrm{FOS} \leq 1}>0.25$. 
Although model uncertainties are present in this study, results are generally consistent with what has been observed historically within the watershed. Interpreted data and assumptions that were sources of model uncertainty in this study were chosen based upon sound geologic principles and comparable data from past research, respectively. Although these data and assumptions have the potential to be inaccurate, they were the best known approximations of site conditions available to the author at the time of this project. Although it could be argued that a basin-wide, fully saturated soil profile is not physically possible, site specific scenarios could occur anywhere in the watershed, potentially leading to fully saturated soil profiles. The February 1996 storm event came close to achieving these conditions (Scott Burns, personal communication 2011). In this case, infiltration systems would concentrate water in the soil, fully saturating the slope, resulting in pore water pressures that ultimately lead to slope failure. This exact situation happened in Portland's West Hills when a residential lawn irrigation pipe burst, causing a home to slide into the canyon below (Burns, 2010). The model appears to be a reasonable approximation of probabilistic slope instability.

The soil conditions and modeling applied in this study have the potential to be applicable to a large area of the West Hills due to the fact that geologic controls on the emplacement of the Cascade Silt Loam soil series causes them to dominate the majority of their surface above $122 \mathrm{~m}$ amsl. Given the results of this study, coupled with similar soil conditions throughout the region, stormwater infiltration should be carefully analyzed or altogether abandoned in the West Hills. The methods used here can be 
quickly and easily used to model the influence of changing hydrologic conditions on slope stability and can be applied in areas where sparse geotechnical data are available. 


\section{Chapter 6: Conclusions}

Infiltrating storm water to increase baseflows as a way to improve watershed health in an urban landscape is an appealing concept. From a slope stability frame of reference, infiltration within the Stephens Creek Watershed appears to be feasible. However, prejudice must be exercised when considering site specific projects. Model results from this study, as well as other work done that addresses slope stability within the watershed, has shown that the Stephens Creek area is prone to slope failure. There have been 23 ancient (Burns and Duplantis, 2010) and 15 historic landslides (Burns et al., 1998) mapped and verified within the watershed since 2008. A combination of deeply incised valleys, low cohesion soils, dense urban development (cuts/fills), and potential paleosols and fragipans that act as aquitards all compound to create potentially low FOS conditions.

The data suggest that total area within the watershed that has $P_{\text {FOS } \leq 1}>0.25$ is $3.7 \%$ and $23.7 \%$ for dry and saturated conditions, respectively. This indicates that the watershed transitions from being relatively stable $(96.3 \%$ of total watershed area having $\left.P_{F O S \leq 1}<0.25\right)$ during dry soil conditions, to being somewhat unstable $(76.4 \%$ of total watershed area having $P_{\mathrm{FOS} \leq 1}>0.25$ ) during saturated soil conditions. Transitioning from dry to saturated conditions increases the combined area that has $P_{\text {FOS } \leq 1}>0.25$ by $19.9 \%$. This means that in an extreme rainfall event and complete infiltration of the soils, nearly $24 \%$ of the watershed could develop landslides. The avoidance area map suggests that infiltration in $38.1 \%$ of the area within the watershed should be avoided completely. 
These areas include steep cut/fill slopes, and naturally occurring steep slopes within Stephens Creek Canyon and its tributaries.

The model employed in this study takes advantage of the random nature of processes that affect slope stability (height of the phreatic surface, depth of soil over a failure surface, and geotechnical parameters of soils). Allowing these variables to vary can also lead to potentially inaccurate results. Although this study modeled extreme best and worst case scenarios, the potential to reach a worst case situation could easily be realized if proper drainage of slopes is not maintained. This situation not only applies to the Stephens Creek Watershed, but also a large area of the West Hills. Therefore, it is recommended that downspout disconnects and stormwater infiltration not be used as a best management practice in stream restoration in the West Hills. 


\section{Future Work}

Future work related to slope stability modeling within the Stephens Creek Watershed could include seismic considerations, although this would likely only indicate that ground shaking would exacerbate the saturated static conditions, which already represent a significant hazard due to infiltration. Another consideration for future work would be to incorporate a time variant groundwater model into PISA-m in an effort to show how changing phreatic conditions affect slope stability. Additionally, with enough data, the incorporation of interpolated rasters derived for every geotechnical parameter in the infinite slope equation could potentially lead to a more accurate model of stability within the watershed. This effort, however, would likely be constrained both temporally and economically. 


\section{References}

Allen, J.E., Burns, M., and Burns, S.F., 2009, Cataclysms on the Columbia: The Great Missoula Floods, $2^{\text {nd }}$ ed.: Portland, Ooligan Press, $224 \mathrm{p}$.

Beeson, M., and Tolan, T., 1989, Geologic Map of the Lake Oswego Quadrangle, Clackamas, Multnomah, and Washington Counties, Oregon: State of Oregon, Department of Geology and Mineral Industries, GMS-59, scale: 1:24 000, 1 sheet.

Birkeland, P., 1999, Soils and Geomorphology, $3^{\text {rd }}$ ed.: New York, Oxford University Press, Inc., $430 \mathrm{p}$.

Box, G., and Draper, N., 1987, Empirical Model-Building and Response Surfaces: New York, Wiley, $669 \mathrm{p}$.

Burns, S., 1996, Landslides in the Portland area resulting from the storm of February, 1996, Environmental, Groundwater and Engineering Geology: Applications from Oregon: Belmont, Star Publishing Company, p. 353-365.

Burns, S.F., Burns, W., James, D., Hinkle, C., 1998, Landslides in the Portland, Oregon Metropolitan Area resulting from the Storm of February 1996: Inventory Map, Database and Evaluation: a report prepared as fulfillment of Metro Contract 905828: Portland, Portland State University, $43 \mathrm{p}$.

Burns, S.F., Burns, W., Hinkle, J., and James, D., 2006, Landslides geohazard map for Portland, Oregon, USA: International Association of Engineering Geologists Paper number 520: The Geological Society of London, $12 \mathrm{p}$.

Burns, W., and Duplantis, S., 2010, Landslide inventory maps of the Lake Oswego Quadrangle, Clackamas, Multnomah, and Washington Counties, Oregon, Interpretive Map 32: Oregon Department of Geology and Mineral Industries (DOGAMI), scale 1:16,000, 1 sheet.

Burroughs, E., and Thomas, B., 1977, Declining root strength in Douglas-fir after felling as a factor in slope stability, U.S. Forest Service Research Paper INT-190.

City of Portland, 2005, Portland Watershed Management Plan: Bureau of Environmental Services, City of Portland, 75 p.

City of Portland, 2008, LiDAR bare-earth digital elevation model (DEM) for urban Clackamas County, Multnomah County, and Washington County, Oregon.

City of Portland, 2009, Stephens subwatershed improvement strategies report: Bureau of Environmental Services, City of Portland, 105 p.

Davis, J.C., 2002, Statistics and Data Analysis in Geology, $3^{\text {rd }}$ ed.: New York, John Wiley \& Sons, $638 \mathrm{p}$. 
Drazba, M.C., 2008, Landslide susceptibility map for shallow landslides for the West Hills of Portland, Oregon using GIS and LiDAR [M.S. thesis]: Portland, Portland State University, $77 \mathrm{p}$.

Evarts, R.C., O'Connor, J.E., Wells, R.E., Madin, I.P., 2009a, The Portland Basin: A (big) river runs through it: GSA Today, v. 19, no. 9, p. 4-10.

Evarts, R.C., Conrey, R.M., Fleck, R.J., and Hagstrum, J.T., 2009b, The Boring Volcanic Field of the Portland-Vancouver area, Oregon and Washington: tectonically anomalous forearc volcanism in an urban setting: The Geological Society of America, Field Guide 15.

Gerig, A., 1985, Soil Survey of Clackamas County Area, Oregon: United States Department of Agriculture, Soil Conservation Service, 197 p.

GPS Surveying Inc., 2002, Source imagery for tile production, Richmond, B.C., 9 total images accessed from http://earthexplorer.usgs.gov/ on 08/09/2012.

Green, G., 1982, Soil Survey of Washington County, Oregon: United States Department of Agriculture, Soil Conservation Service, $90 \mathrm{p}$.

Green, G., 1983, Soil Survey of Multnomah County, Oregon: United States Department of Agriculture, Soil Conservation, $146 \mathrm{p}$

Haneberg, W., 2000, Deterministic and probabilistic approaches to geologic hazard assessment: Environmental and Engineering Geoscience, v. 6, no.3, p. 209-226.

Haneberg, W., 2007, PISA-m: Map-based probabilistic infinite slope analysis, version 1.0.1 user manual: http://www.haneberg.com/downloadables/manual_1_0_1.pdf.

Haneberg, W.C., Cole, W.F., and Kasali, G., 2009, High-resolution LiDAR-based landslide hazard mapping and modeling, UCFS Parnassus Campus, San Francisco, USA: Bulletin of Engineering Geology and the Environment, v. 68, p. 263-276.

Hammond, C., Hall, D., Miller, S., and Swetik, P., 1992, Level I stability analysis (LISA) documentation for version 2.0: general technical report INT-285. U.S. Forest Service Intermountain Research Station, Ogden, UT, 190 p.

HARZA Engineering Company, 2000, Riparian and stream habitat assessment of Stephens Creek, $51 \mathrm{p}$.

Johnson, R., and DeGraff, J., 1988, Principles of Engineering Geology: New York, John Wiley and Sons, $497 \mathrm{p}$.

Lawes, J.L., 1997, Geochemistry, stratigraphy and provenance of the Portland Hills Silt in the Tualatin Mountains, Portland, Oregon [M.S. thesis]: Portland, Portland State University, 243 p. 
Lentz, R., 1981, The petrology and stratigraphy of the Portland Hills Silt - a Pacific Northwest loess: Oregon Geology, v. 43, n. 1, p. 3-10.

National Oceanic and Atmospheric Administration (NOAA), 2009, http://www.wrh.noaa.gov/pqr/climate/pdx clisummary.php. Accessed 2010-05-04.

R Core Development Team, 2012, R: A language and environment for statistical computing, Vienna. Available at: http://www.R-project.org.

Schmidt, K., Roering, J., Dietrich, W., Montgomery, D., and Schaub, T., 2001, The variability of root cohesion as an influence on shallow landslide susceptibility in the Oregon Coast Range: Canadian Geotechnical Journal, v. 38, number 5, p. 995-1024.

Stephenson, A.G., 2012, EVD: extreme value distributions: R News, v. 2, number 2, p. 31-32.

Wolfram, S., 1999, The Mathematica Book, $4^{\text {th }}$ ed.: Cambridge University Press, Cambridge, U.K., $1470 \mathrm{p}$.

Wuensch, K., 2010, One-way multiple comparison tests, http://core.ecu.edu/psyc/wuenschk/StatsLessons.htm. Accessed 2012-12-05. 
Appendix A: Example of a geotechnical report from BES Public Works Database

TABLE 6: SUMMARY OF LABORATORY TEST RESULTS(SOLL)

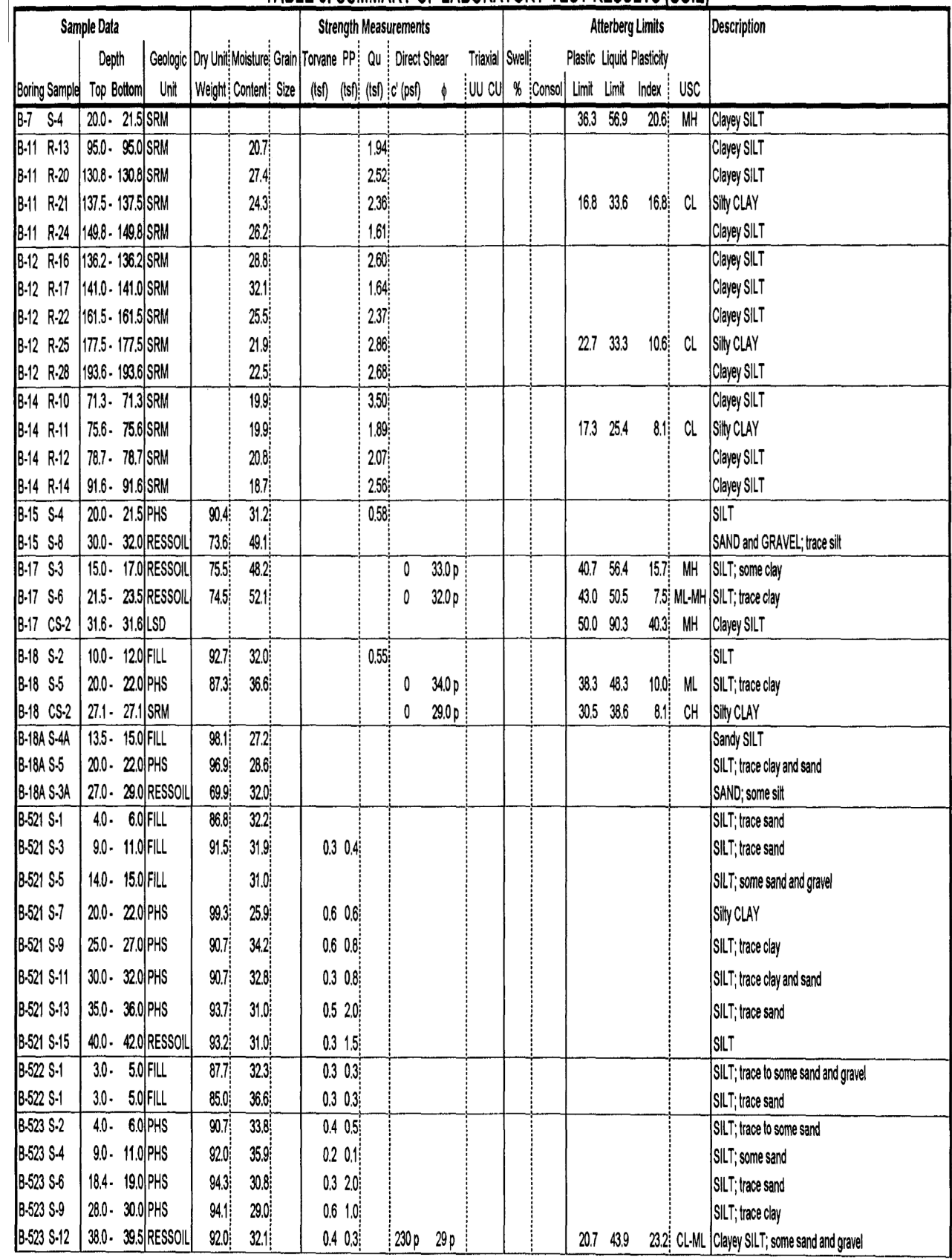




\section{Appendix B: R-scripts}

\# This script is a function to perform an F-test of two sample variances as described in Davis (2002, p.75)

\# the function asks for a confidence level (alpha) and two arrays; then calculates a test statistic and table value to determine if null hypothesis is rejected or, fails to reject

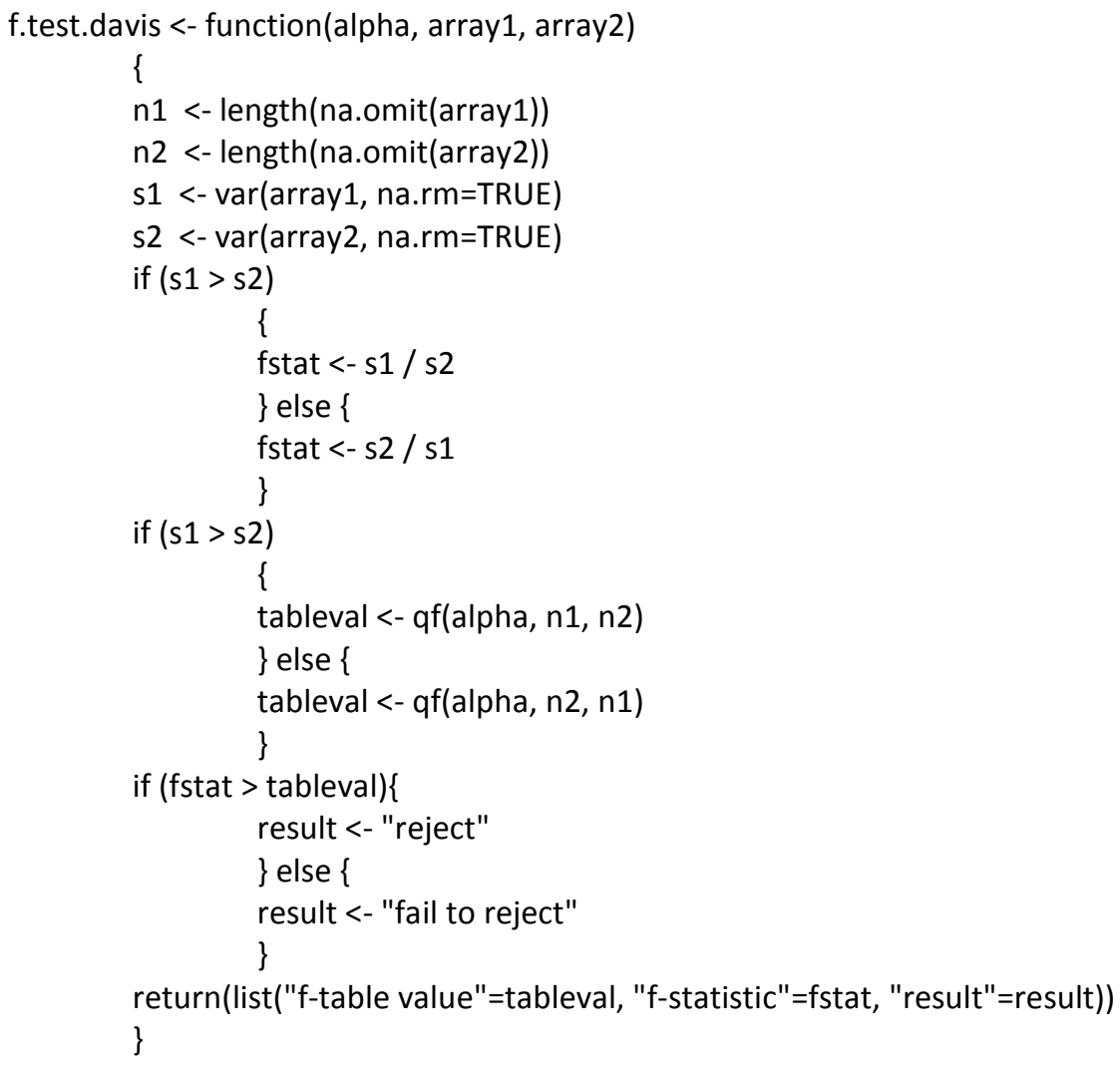

\# This script is a function to perform a two-tailed t-test of two sample means with equal variance and unequal sample sizes; as described by Wuensch (2010) \# the function asks for a confidence level (alpha), mean square error (MSE) from an omnibus ANOVA, and two arrays; then calculates a test statistic and table value to determine if null hypothesis is rejected or, fails to reject

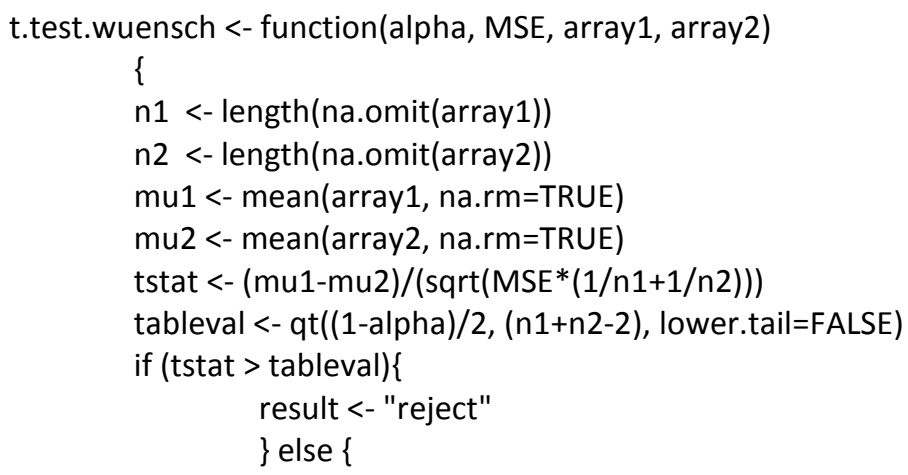




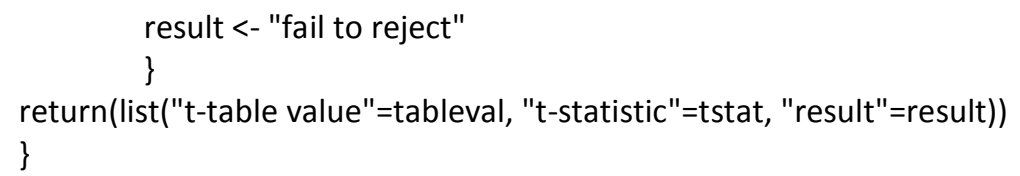

\# This script is a function to perform a two-tailed t-test of two sample means as using Welch's ttest; which assumes unequal variance and unequal sample size

\# the function asks for a confidence level (alpha) and two arrays; then calculates a test statistic and table value to determine if null hypothesis is rejected or, fails to reject \# This function also uses the Welch-Satterthwaite equation to determine degrees of freedom for the table value; given by: tableval <- $\left((\mathrm{s} 1 / \mathrm{n} 1+\mathrm{s} 2 / \mathrm{n} 2)^{\wedge} 2\right) /\left(\left(\left((\mathrm{s} 1 / \mathrm{n} 1)^{\wedge} 2\right) /(\mathrm{n} 1-1)\right)+\right.$

$\left.\left((\mathrm{s} 2 / \mathrm{n} 2)^{\wedge} 2\right) /(\mathrm{n} 2-1)\right)$

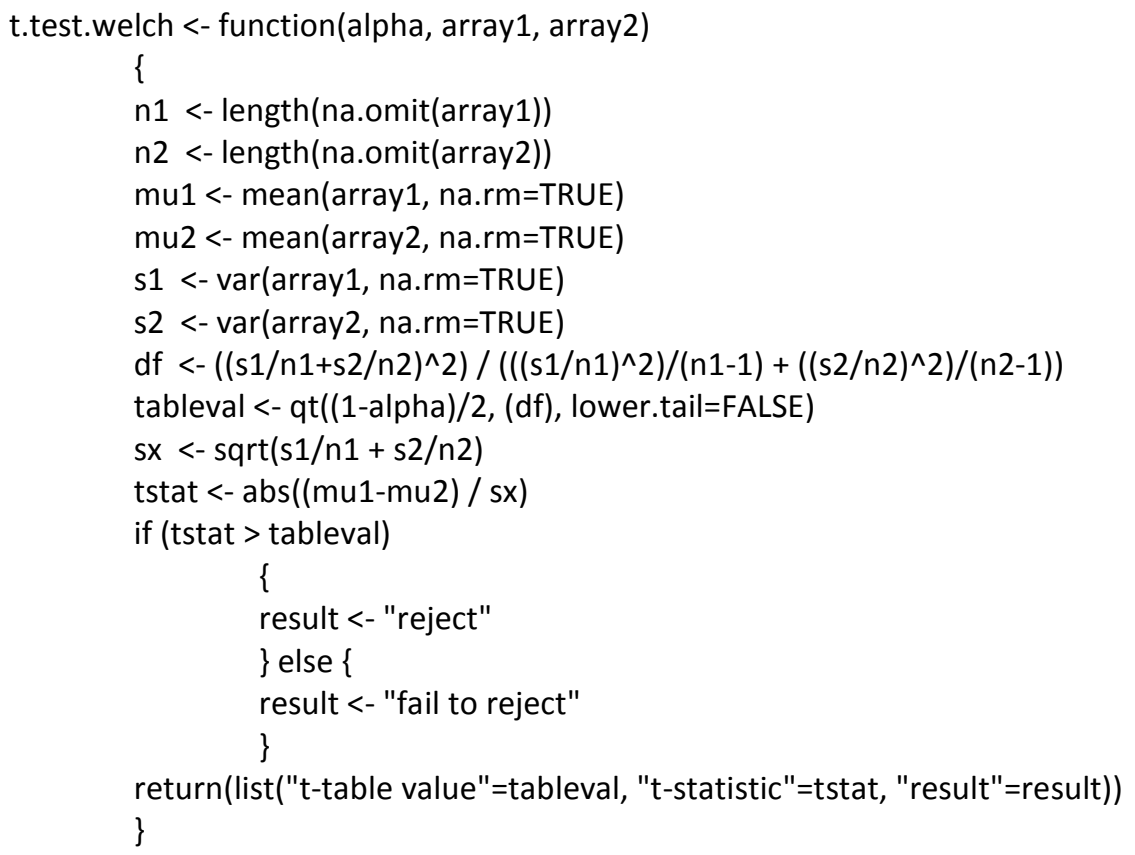

\# This script is a function to perform a chi-squared test against a normal PDF \# the function asks for an input array, number of breaks, and a level of significance (alpha) \# and returns chi-squared value, table value, and result of test

f.chisqr.tst <- function(data, breaks, alpha) \{

obs <- as.matrix(na.omit(data),1)

$x<-$ mat.or.vec(length(obs), 1)

cntr <- mat.or.vec(breaks,1)

cntr2 <- mat.or.vec(breaks,1)

exp $<-$ length(obs)/breaks

dof $<$ - breaks-3

chi <- mat.or.vec(breaks,1)

for ( $\mathrm{j}$ in $1:($ length(cntr) $))\{$ for (i in 1:length $(x))\{$

$x[i]<-($ obs[i,1]-mean(data, na.rm=TRUE)) / sd(data, na.rm=TRUE) 


$$
\begin{aligned}
& \text { if }(j==1)\{ \\
& \text { if }(x[\mathrm{i}]<\text { qnorm }((1 / \text { breaks }) *(j)))\{ \\
& \operatorname{cntr}[j]<-\operatorname{cntr}[j]+1\}\} \\
& \text { if ( } \mathrm{j}>=2 \& \& \mathrm{j}<=(\text { length(cntr) }-1))\{
\end{aligned}
$$

qnorm $((1 /$ breaks $) *(j)))\{$

if $(x[i]>=$ qnorm $((1 /$ breaks $) *(j-1)) \& \& x[i]<$

$$
\begin{gathered}
\operatorname{cntr}[j]<-\operatorname{cntr}[j]+1\}\} \\
\text { if }(j==\text { length }(\text { cntr }))\{ \\
\text { if }(x[i]>\operatorname{qnorm}((1 / \text { breaks }) *(j-1)))\{ \\
\operatorname{cntr}[j]<-\operatorname{cntr}[j]+1\}\}\}
\end{gathered}
$$

for (I in 1:(length(cntr)))\{

$$
\text { chi[l] } \left.\left.<-(\operatorname{cntr}[I]-\exp )^{\wedge} 2 / \exp \right\}\right\}
$$

chi2stat <- sum(chi)

chi2tabl <- qchisq(1-alpha, dof)

if (chi2stat $<=$ chi2tabl) \{

result <- "fail to reject"\}else\{ result <- "reject"\}

return(list("alpha"=alpha, "DOF"=dof, "chisq statistic"=chi2stat, "chisq crit value"=chi2tabl, "result"=result))\} 
Appendix C: Example parameter file

\author{
static probability \\ in_format arc \\ out_format arc \\ dem.asc \\ soils.asc \\ trees.asc \\ results.asc \\ gw 62.428 \\ an 0 \\ dn 0 \\ IA 0 \\ minslope 3 \\ z_err 0.5482 \\ soils 2 \\ phi normal 27.83 .80 \\ cs normal 8694430 \\ d extreme 24200 \\ h uniform 000 \\ gs normal 12540 \\ gm normal 11760 \\ phi extreme 28.81 .40 \\ cs normal 9215800 \\ d normal 2480 \\ h uniform 000 \\ gs normal 126140 \\ gm normal 111910 \\ trees 2 \\ cr normal 2611040 \\ q uniform 000 \\ cr normal 000 \\ q uniform 000
}

